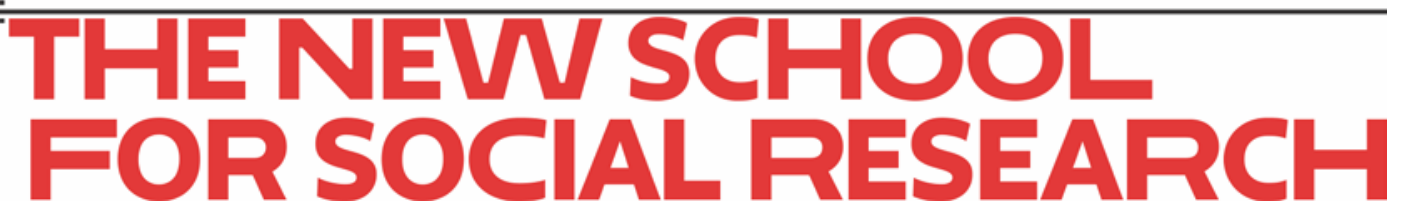

Rishabh Kumar

\title{
Capital and the Hindu rate of growth: Top Indian wealth holders 1961-1986
}

October 2016

Working Paper 08/2016

Department of Economics

The New School for Social Research 


\title{
Capital and the Hindu rate of growth: Top Indian wealth holders 1961-1986
}

\author{
Rishabh Kumar \\ The New School for Social Research*
}

October 7, 2016

\begin{abstract}
Did India's stagnant growth performance until the 1980s increase or decrease the wealth of the elite? Using estate tax data I compute a series which highlights the relative importance of top wealth holders in India between 1961-1986. I find that a combination of policies and shocks were able to significantly depress the personal wealth of the Top $0.1 \%$ over this period. A portfolio decomposition by asset categories for the rich reveals that there was a $U$ shaped trend in the average value of movable assets while wealth invested in land significantly declined. Disparity within top wealth groups also follows a shrinking and swelling, consistent with the intervention of the state in private capital. These results have implications for the equalizing forces inherent in tax policy vis-a-vis the rich and the role of the state in regulating capital in poor nations.
\end{abstract}

JEL Classification: H1, N3, O1

Keywords: Wealth, India, Estate Multiplier

*Department of economics at the New School for Social Research (New York). For contributions and comments, I am grateful to Jan Keil, Mark Setterfield, Duncan Foley, Tom Michl, Thomas Piketty, Sanjay Reddy, Paulo Dos Santos, Vimal Balasubramaniam and participants at the NSSR macro lunch, UMass-New School workshop, CUNY Stone Center and other seminars. I am indebted to Suranjali Tandon for assisting with compilation of data utilized in this project and to anonymous members of the income tax department for their insights on tax policies. 


\section{Introduction}

This paper is a historical study of top Indian wealth and tries to answer a very important and unaddressed question - how does the developmental experience interplay with the concentration of wealth amongst the rich incumbents of a very poor and capital scarce nation? My exposition on this issue is done from the perspective of independent India over a period commonly referred to as the Hindu rate of growth (1961-1986). ${ }^{1}$

The concern in development economics has been predominantly (and perhaps rightly) on the alleviation of poverty and growth of per capita incomes. Yet in the infancy of industrial capitalism when today's rich were beginning to enrich themselves, Adam Smith wrote on the wealth rather than the income of nations. Few, if any studies have fully grappled with this issue for India over the long run of history. In the formation of a newly independent economy the accumulation and distribution of private wealth would have held great significance for the trajectory of equitable growth. For example, did the wealthy further enrich themselves during the oft-cited low growth era in India? Of particular interest is the fact that the Indian state was concerned with raising revenue from the capital surplus of the wealthy in keeping with its purpose of creating social and economic equity. The latter is as much a question of uplifting the poor as it is checking the unprecedented rise of the elite. An interesting facet of this era is that the Indian government was never anti-capital ${ }^{2}$ although it did try to project an anti-elite streak over the initial reign of Indira Gandhi starting in 1966. There are no official historical estimates of the wealthiest persons in India barring popular tales on the inventory of some of the wealthiest princes in the past. While it may be the case that the mixed economy experiment throughout the period 1947-1985 (the beginning of industrial reforms) did result in the formation of national capital, there is no information on the simultaneous fate of personal wealth. The major hurdle in conducting any such study of a similar scope and timescale as the well known book by Piketty (2014) is that there is a chronic shortage of high quality administrative data on personal wealth.

In my paper, I try to take steps to resolve this lacuna in Indian economic history. Using novel data from estate tax returns and mortality tables of insured Indians, I construct a new dataset of top Indian wealth holders through the period 1961-1986. The underlying model (the estate multiplier technique) is common in other historical studies of wealth across the world because often individuals are not required to disclose their assets, except for the purposes of inheritance at death. Unfortunately these are the only years for which reliable data was available because the estate tax was repealed in 1985 and hence a longer run time series could not be estimated. I argue that these are the best data on hand to assess Indian wealth because of perennial problems with tax evasion and under-reporting of wealth. The resulting database is then used to compute the wealth of the top fractiles (starting with the Top $0.1 \%$ ) and track the metamorphosis of wealth over time between land and movable assets. Using the GDP and associated shorter series I show trends in the importance of the elite vis-a-vis national income and the degree of disparity within this class itself. I further analyze these results by checking for a possible undervaluation effect through which wealth seeks to escape tax authorities and earn a higher effective rate of return. The underlying trends are then rationalized on the basis of statistical models of decentralized portfolio activity in conjunction with state policies on private

\footnotetext{
${ }^{1}$ The term Hindu rate of growth was developed by the Indian economist Raj Krishna to typify a country of (mostly) Hindus which did not see rates of economic growth seen in similar newly independent, developing and neighboring countries such as South Korea, Taiwan, Pakistan and Bangladesh. The blame is commonly attributed to archaic controls on the movement of capital and regulation of industrial policy. See Rodrik and Subramanian (2005)

${ }^{2}$ See Patel (1986) on Nehru and the commanding heights philosophy.
} 
capital. Tax compliance in India has always remained questionable so I stress that these data are not the bottom line but the start of such estimations, particularly as more administrative data becomes computerized.

Two main findings emerge from my analysis of the trends. Firstly the regulatory squeeze, inflation shocks and a sequence of anti-elite policies on private wealth resulted in a sharp decline of the wealthy relative to national income. In nominal terms, the threshold to be counted amongst the Top $0.01 \%$ went through a $U$ shaped trend with a trough in 1976 during the emergency period in Indian history. In the mid 1960s, the wealthiest 200,000 families could alone finance a few months of national income. By the mid 1980s their wealth could perhaps finance a couple days worth of GDP at best. This decline can be traced to the nationalization of various private assets, land reforms and confiscatory tax policies on wealth and capital gains. The observed trend amongst the wealthy elite is consistent with the findings of Banerjee and Piketty (2005) for top incomes. The composition of private wealth amongst the rich also transformed over this period. The fall in the real value of private assets, which started in the 1960s, continued through to the mid 1980s for immovable assets in urban areas and agricultural land. But at the same time this downward trend was reversed for movable assets such as equity, securities and other financial assets coinciding with tax breaks on capital gains starting in 1978-79. By 1985, the average portfolio made up of movable wealth had fully recovered its value prior to the inflation shocks of 1973. The second finding concerns the degree of disparity within the elite themselves and mimics the fall and rise of the real value of movable assets. In the $1960 \mathrm{~s}$, the Top $0.01 \%$ held a large share of the total wealth within the Top $0.1 \%$. This share however continued to decline through to the mid 1980s because the downfall of the Top $0.1 \%$ was mostly due to the fall of the Top $0.01 \%$. In the intermediate fractiles (between the Top $0.1 \%$ to Top $0.01 \%$ ) also there was an upward trend in inequality starting with the relaxation of direct taxes on wealth and investment income in the late 1970s. The biggest relative gainers over this period were thus those just below the Top $0.01 \%$. Comparison with a series on total household capital starting 1981 reveals the share of the Top $0.01 \%$ to be around 1-2\% between 1981-1986.

The contributions of this paper relative to the existing literature are twofold. To my knowledge this is the first (and only) series on top wealth for India for any historical period. These estimates are comparable to the international database put together by the World Wealth and Income Database (WWID). Data on Indian wealth are very limited and while infrequent (decennial, at best) national wealth estimates were compiled by Raymond Goldsmith ${ }^{3}$ till 1975, there is no consistent estimate of private wealth. This problem continues to the present where the only estimates of the wealthiest Indians (never more than the richest 400) are either put together by financial magazines like Forbes ${ }^{4}$ or research wings of investment banks like Credit Suisse. Bagchi (1974) tried to make an estimate of personal wealth, but his series was limited to one year (1969-70) and used an arbitrary capitalization factor on income tax returns so that wealth inequality was basically an exactly a replica of capital income inequality. The second contribution of this paper is that it puts into context the fate of the wealthy with regard to a high unstable period in Indian economic history. While I cannot claim to explain away the patterns in the wealth data, the consistency of the trends amongst the elite with the various shocks during this period are quite strong. The historical literature has very rarely, if ever focused on a discussion of India's growth performance with regard to the absolute rich. The simplest takeaway, using a model of wealth and the well known Pareto law, is that regulatory controls can contain the concentration of wealth by limiting the turnover activity of these portfolios. Had there

\footnotetext{
${ }^{3}$ See Goldsmith (1983)

${ }^{4}$ A study of the tail of the wealthiest 400 Indians in the mid 2000s was conducted by Sinha (2006)
} 
been regular data on the total wealth of Indian households, a further analysis could have revealed whether the decline of the elite was matched by a rise or fall in personal wealth. This question remains a work in progress as retrospective balance sheets are developed.

The rest of the paper is organized as follows. The next section highlights the data and technique used to make estimates over the period 1961-1986. After this, results are presented and followed by a discussion section. Here I analyze these trends in historical perspective, along with a counterfactual exercise to check for under-reporting of real estate. The last section concludes. A detailed appendix is attached at the end for interested readers. This goes in-depth with regard to data sources, the literature on Indian taxation and the various tax acts from which the data have come to fruition. Technical details on the estate multiplier model, its shortcomings and the counterfactual experiment for real estate are also discussed.

\section{Data and methodology}

\subsection{Data on wealth}

The data used in this paper is sourced from reports of the All India Wealth Tax, Gift Tax and Estate Duty Statistics (AIWGE), compiled by the tax authorities in the Central Board of Direct Taxation

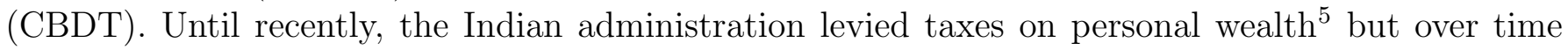
this act was diluted and its ability to catch tax evasion had been in question since the beginning. ${ }^{6}$ Without effective penalties and a low likelihood of being caught, the collection of wealth taxes has been very low historically and the percentage of tax units captured in this scheme is too low and unreliable to draw conclusions. Taking a realistic census of personal wealth is very problematic and though India remained one of the few countries with a wealth tax, consistent details on top wealth holders can best be gauged by sampling estate taxes. Since inheritance of property must be registered with administrative authorities, it is less prone to tax evasion. For a detailed discussion on the pros and cons of estate versus wealth tax data see Appendix A.

The estate tax was levied starting 1953 and abolished in 1985. Hence the data coverage in this paper ends with 1986 and starts with the earliest available issue of estate records (1961). Detailed hardcopy reports of the AIWGE are available from 1966 to $1990^{7}$ but the reliability and consistency of data is limited to 1986. For interested researchers I have created a documented digital database in accessible spreadsheets to go with this paper. The concept of personal wealth is exactly reproduced from official documentation by the Indian tax authorities and details on definitions are listed in the appendix. $^{8}$ Thus the net value of the estate as per administrative definitions is used to compute total and average wealth per estate. One shortcoming of not possessing detailed microdata is that while we can see the size of estates with their respective frequencies, we cannot see simultaneously the decomposition of assets by type for these estate holders. Thus all portfolio decompositions capture the entire wealthy class rather than exact fractiles such as the Top 0.1\%. From 1961 to 1986, wealth

\footnotetext{
${ }^{5}$ The wealth tax came into being with the Wealth Tax Act of 1957, following the recommendations of the Kaldor Committee Report of 1956. See Kaldor (1956)

${ }^{6}$ See the discussion on evolution of Indian tax policy and the reform of central taxes in Rao et al. (2006)

${ }^{7}$ Statistics on estate duty are reported till 1990 but only cover older cases since the tax itself was removed in 1985 and hence we cannot ascertain the comparative validity of these years

${ }^{8}$ See Appendix A.1.1
} 
can be decomposed into real estate and movable assets. Movable assets can be further decomposed into equity, dividends, gold etc starting 1966.

The Reserve Bank of India does not follow the otherwise common international practice of releasing market value household balance sheets. ${ }^{9}$ Although historical estimates (infrequently and only till 1975) on national wealth were imputed by Goldsmith (1983), there is no figure to capture private or household wealth separately. Hence at no point in this paper do I present the shares of top wealth holders in personal wealth, instead choosing to capture the importance of the elite by taking fractile specific wealth to national income ratios. National income (market price GDP) and household income (for tax units) are taken from the National Account Statistics (NAS), all nominal variables being deflated by the Consumer Price Index (CPI) to allow comparison with other studies.

\subsection{Estate multiplier model}

To estimate the wealth of rich Indians this paper uses the estate multiplier method, pioneered by Lampman (1962) for the United States. The assumption in this class of methods is that death selects a sample (recorded in the estate tax) which can then be used to reproduce a distribution of wealth amongst the living. Due to the fact that wealth is so difficult to measure otherwise, this model is commonly used to calculate the share of top groups in the population. Various studies of the elite in the rich world, such as Atkinson and Harrison (1978), Kopczuk and Saez (2004) and Piketty et al. (2006) have utilized the estate multiplier. The US Internal Revenue Services also periodically uses this technique to produce estimates of the wealthiest Americans. After constructing a dataset using the estate multiplier, I found a much larger coverage of total tax units compared to the wealth tax with the number of estates above exemption limits increasing over time as a result of inflation and population growth.

The estate multiplier inverts the probability of being a decedent, thus for any rate of mortality $(m)$ an estate $(P)$ represents $\left(\frac{P}{m}\right)$ living wealth holders. For example if the mortality rate for adults within some age bracket is is $0.1 \%$, then a decedent represents $\frac{1}{0.001}$ (i.e 1000) persons for the age bracket. The sample of estates derived from estate tax returns is therefore multiplied to produce a wealth distribution for persons above the exemption limit. The model in this paper uses a slightly different population control, as opposed to similar studies conducted in other countries. In India, the estates of decedents stand for tax units rather than purely individuals due to complications arising from the Hindu law tradition ${ }^{10}$ in inheritance and classification of property. More details on the choice of population controls are available in Appendix A.2.

The choice of mortality rates is crucial to the estate multiplier model. Population wide mortality rates, as reported in health studies may not necessarily correspond to elite classes particularly when we are studying the case of a very poor economy with very high socioeconomic and health access disparities. After nationalization, the Life Insurance Corporation (LIC) embarked on a multi year (1970-1973) study of mortality for assured Indians, i.e those who purchased life insurance contracts. Since such people are likely to be wealthier than the average Indian, I use these mortality tables for the estate multiplier. The tables are directly reproduced from Joshi and Venkataraman (1980) who extensively review the mortality measurements of the LIC and other Indian insurance providers.

\footnotetext{
${ }^{9}$ The RBI has a household capital series, however these only start in 1980 and use perpetual inventory methods which are not ideal for our purpose.

${ }^{10}$ The Hindu Succession Act of 1956
} 
By combining estate data with these mortality tables I arrive at a final estimate of living Indians whose wealth surpasses the exemption limits for the estate duty. Extensive details on the potential shortcomings of the estate multiplier method, issues involved with age and gender differentials and the construction of the 1961-1986 Indian estate multiplier are listed in Appendix B.

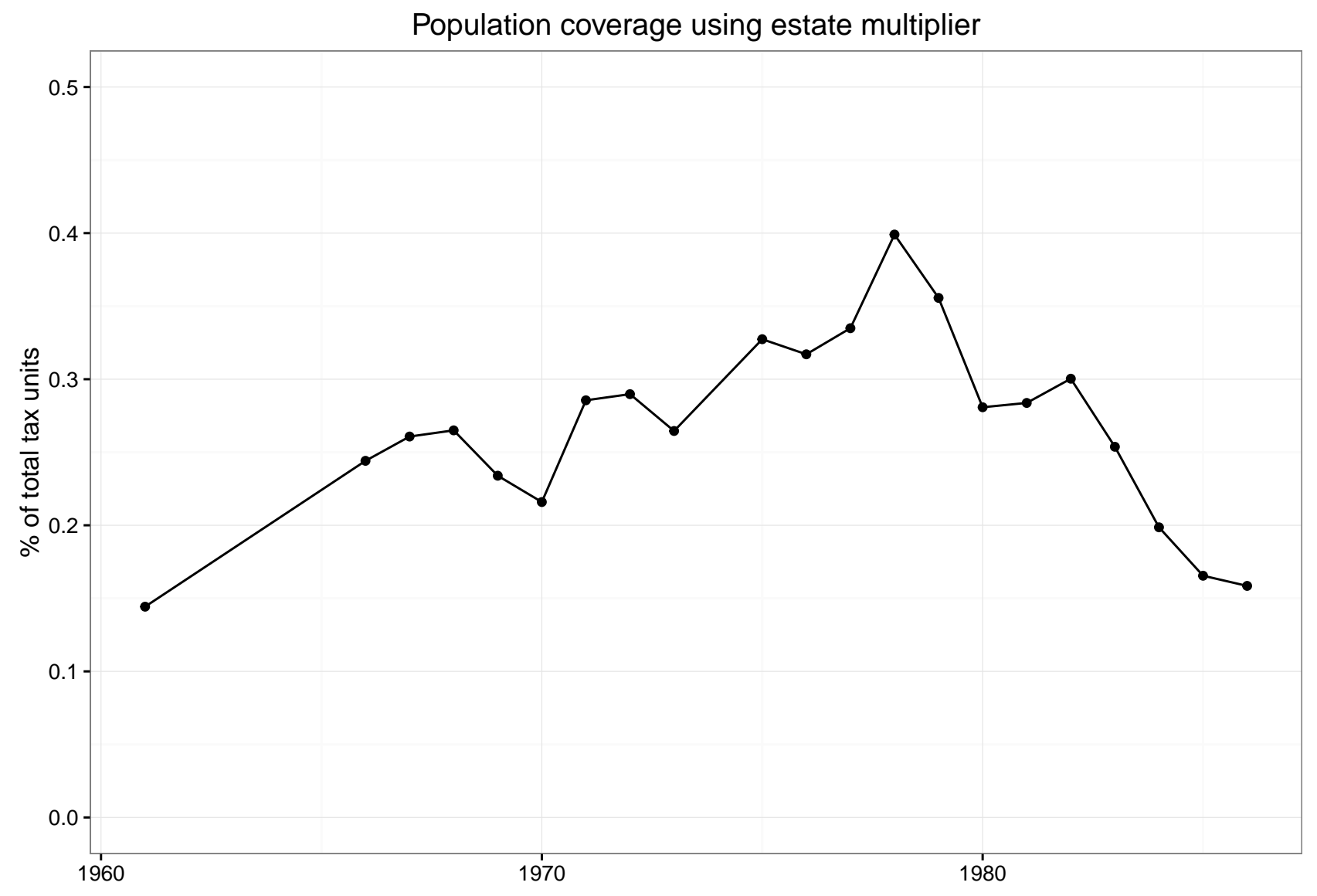

Figure 1: Time series of tax units covered by the estate multiplier. Author's computations

The resulting dataset captures between $0.3 \%$ to $0.12 \%$ of the total Indian tax units in this period. Thus the lowest possible time series of wealth holders is the Top $0.1 \%$. This is already an indicator that wealth was extremely concentrated in India since so few potential estates exceeded the estate duty exemptions. Precise fractiles are calculated using Pareto interpolation. I tested and confirmed the distribution of estates for the Pareto law which is a statistical regularity for the upper tails of wealth and income distributions. Appendix $\mathrm{C}$ lists details on the methodology of computing top shares and related literature which uses the same interpolation technique. From this resulting series, average and total wealth are computed for the Top $0.1 \%$, Top $0.05 \%$ and the Top $0.01 \%$.

\subsection{Dealing with the unaccounted economy}

A long running thematic issue with measurement of economic data in India is the degree of tax evasion and unaccounted incomes and wealth. There is no doubt that there was (and remains till date) a significant amount of wealth, as there is income, hidden from the tax authorities. Having long been a concern of policymakers, the two black economy experts (Shankar Acharya and Arun 
Kumar) for this period did extensive reports to estimate the degree of unaccounted income. Since there are no long run wealth estimates, details on these are less forthcoming though Acharya (1986) did cover real estate for Delhi, Bombay and Madras. Kumar (2002) has a detailed, long study of the black economy in India and presents estimates of unaccounted incomes through the various sectors and industries. By 1990-91, he estimated the black economy to be around 35\% of GDP.

The consensus seems to be that the inefficiencies of the wealth tax (discussed in Appendix A) make it unreliable to draw conclusions of the wealth of rich and elite Indians, who may be guilty of evading taxes. In particular the wealth tax under lax measures to ensure compliance generates a burden on the taxpayer's income and the effective marginal incidence generates a high rate of return to evasion. For example Acharya (1986) proposes that the joint effect of capital income taxation was an effective rate of $97.5 \%$ for those with net wealth above Rs 1.2 million. Secondly, the imposition of nominal level tax brackets increases the incentive to evade since inflation (always a major issue in India) causes what Acharya and associates call bracket creep ${ }^{11}$. The optimal evasion model by Srinivasan (1973) covers these issues from a theoretical perspective with compliance decreasing as income levels (such as capital gains) rise and increasing with the probability of detection.

There are at least three reasons why the estate multiplier approach maybe the best tool to deal with unaccounted wealth. Firstly, estate tax as compared to the wealth tax is a one time tax (at death) and hence the burden on the taxpayer (the recipients of bequest) is not annual. The motivation to under-report assets or undervalue them at least is lower. The check on transmission of inter vivos gifts (to evade eventual estate duty) also acts as a useful deterrent on individuals anticipating death. Secondly, estate duty may cover movable assets particularly financial assets quite well but real estate undervaluation remains an issue. Even in this case, estates comprise the wealthiest families of India considering the high exemption limits and scrutiny of these properties has been more decisive than say low valued properties. As opposed to an annual levy on net worth, registration of bequests from the estates and will of decedents at least requires a disclosure of asset composition with the administrative authorities.

Third, the concern of black economy experts has been mostly with official underestimation of GDP and related flows such as personal income and capital gains, so that by taking a ratio of estate (or fractile) wealth to GDP I am in a sense normalizing some of the undervaluation in the numerator (wealth) with the already (officially) underestimated denominator. If the estate duty was a policy tool of comparatively reliable compliance, then this wealth to GDP ratio creates an upward bias in measuring the importance of the elite. Any downfall in elite wealth relative to national income is therefore cognizant of asset under-reporting (if any) and reflects a trend of conceptual significance wealth may actually be declining. These data are no doubt fragile to continuous efforts of evasion but perhaps reasonably face the challenges for the purpose at hand.

\section{Results}

The computations on the compiled data lead to some very interesting results, summarized in this section. Beginning with thresholds, averages and relative ratios of top wealth holders, I next present

\footnotetext{
${ }^{11}$ As the tax unit's wealth rises in nominal terms, their tax rate increases but in real terms there may have been no growth and instead inflation creeps them into a higher bracket
} 
comparisons with top incomes over the same period along with evolution of wealthy portfolios and measures of disparity within the rich.

\subsection{Top wealth holders through Hindu growth}

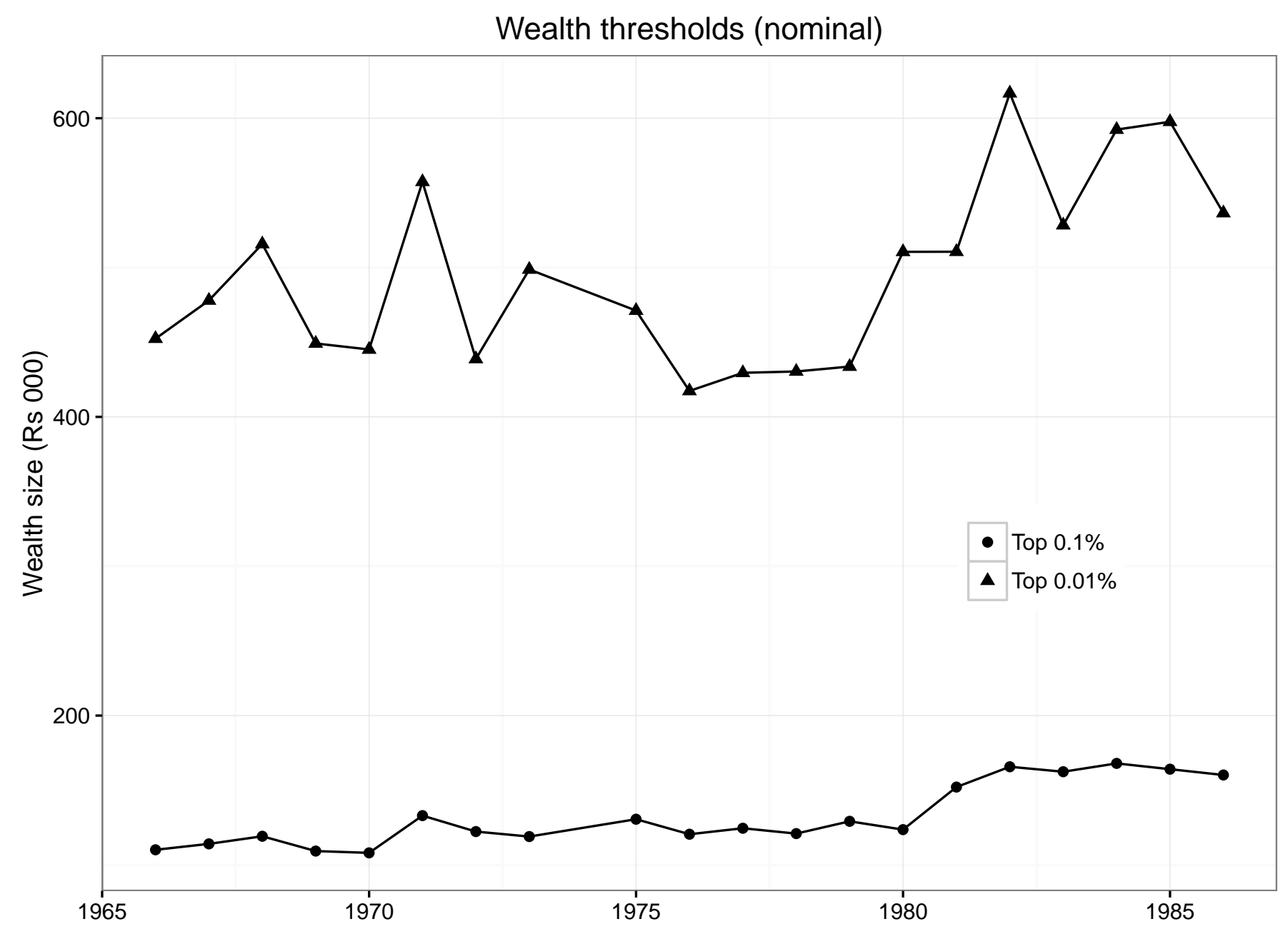

Figure 2: Author's computations

Nominal thresholds to be counted amongst the Top $0.1 \%$ and Top $0.01 \%$ are presented in the above figure. In 1966, the Top 0.1\% comprised approximately 200,000 tax units which rose to about 308,000 tax units by 1986. The growth in inflation unadjusted thresholds ${ }^{12}$ for this group was approximately $2 \%$ with transitional jumps occurring in 1971 and 1981 i.e the threshold noticeably increases around these years. For the super elite (i.e the Top 0.01\%) these thresholds evolved more erratically with a noticeable reduction occurring between 1973 and 1980 followed by a strong resurgence which pushed these nominal cutoffs to over Rs 500,000. The fact that these nominal thresholds declined in the 1970s for the super elite is particularly noteworthy, because such a demise is not evident for the Top $0.1 \%$ and all else being equal points to a stronger decline at the absolute top of the elite themselves.

\footnotetext{
${ }^{12}$ From Rs 110,000 in 1966 to around Rs 160,000 by 1986
} 


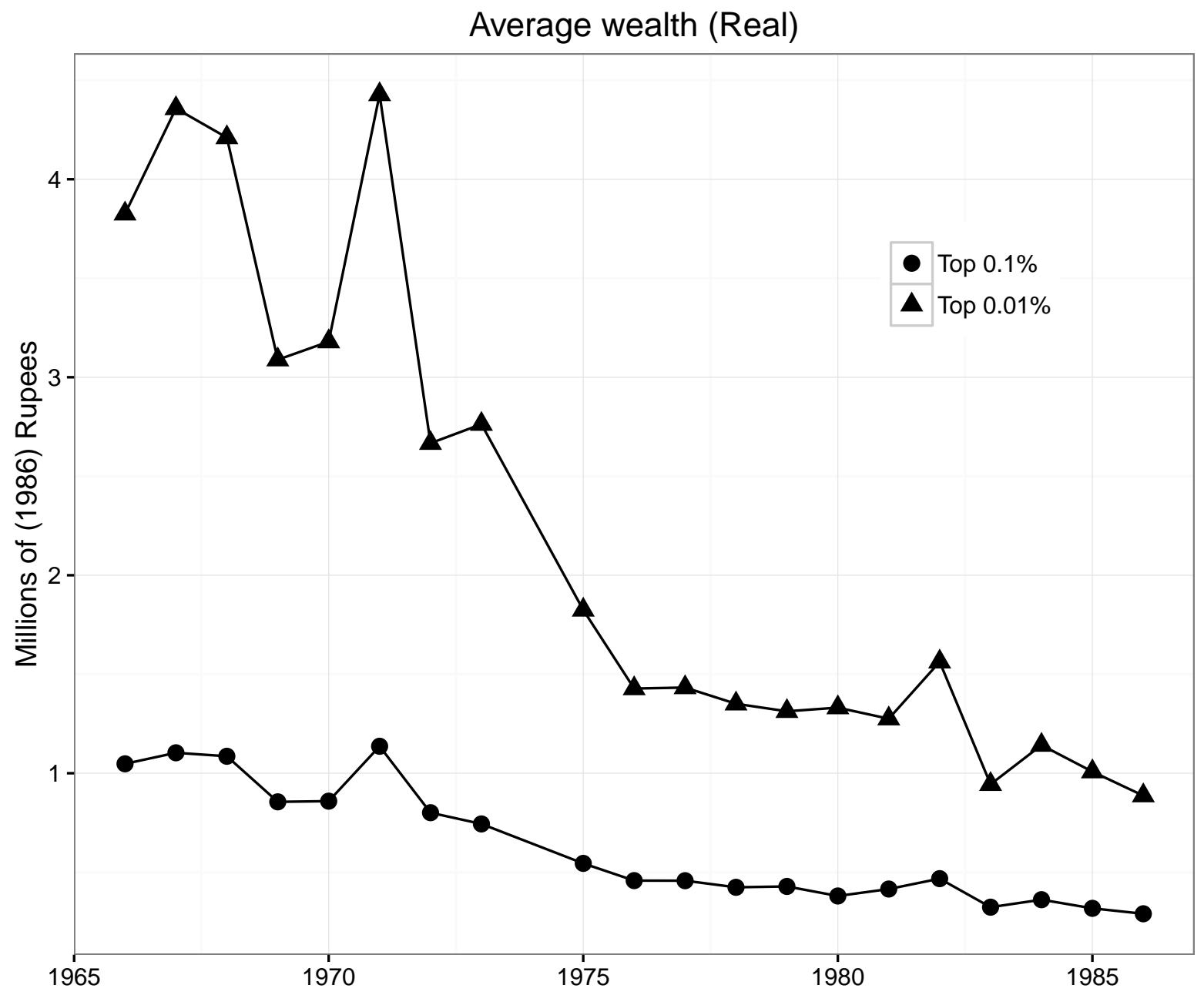

Figure 3: Author's computations

As it turns out, nominal growth flatters the underlying patterns of wealth accumulation - inflation significantly undermined the value of assets. Figure 3 presents the trends in average wealth levels within the Top $0.1 \%$ and Top $0.01 \%$ at 1986 prices. Over the period 1966-1986, there was strong decline in average wealth amongst the elite - so much so that in real terms the average wealth of the Top $0.01 \%$ by 1986 would have been more typical of a member of the Top $0.1 \%$ in 1966 . At the beginning, average wealth in the top $0.01 \%$ was Rs 4 million but a persistent demise in the real value of their wealth over 1971-1976 reduced this to around Rs 1.5 million. Hereafter average levels stabilized for both the Top $0.1 \%$ and Top $0.01 \%$. For the former group the decline occurred over the same period (1971-76) but at a less dramatic rate, basically halving average (group) wealth by 1977. In short, while the decline affected the entire 99.9th percentile, it was relatively more severe for the 99.99th percentile.

\subsubsection{The importance of the wealthy elite in national and personal income}

A more complete picture of the importance of wealth accumulation can be assessed via the ratio of wealth to national income. In this case, the figure below presents the (nominal) wealth of the Top $0.1 \%, 0.05 \%$ and $0.01 \%$ as a share of national income (market price, nominal GDP). Between 1966 
and 1971, Top $0.1 \%$ wealth was around $14-15 \%$ of GDP or just under two months of national income. This ratio fell to $5 \%$ by 1980 and declined even further to about $3 \%$ by 1986 . For the Top $0.05 \%$ and Top $0.01 \%$ the trends are similar with the respective decline by 1986 being $2 \%$ and $1 \%$ of GDP.

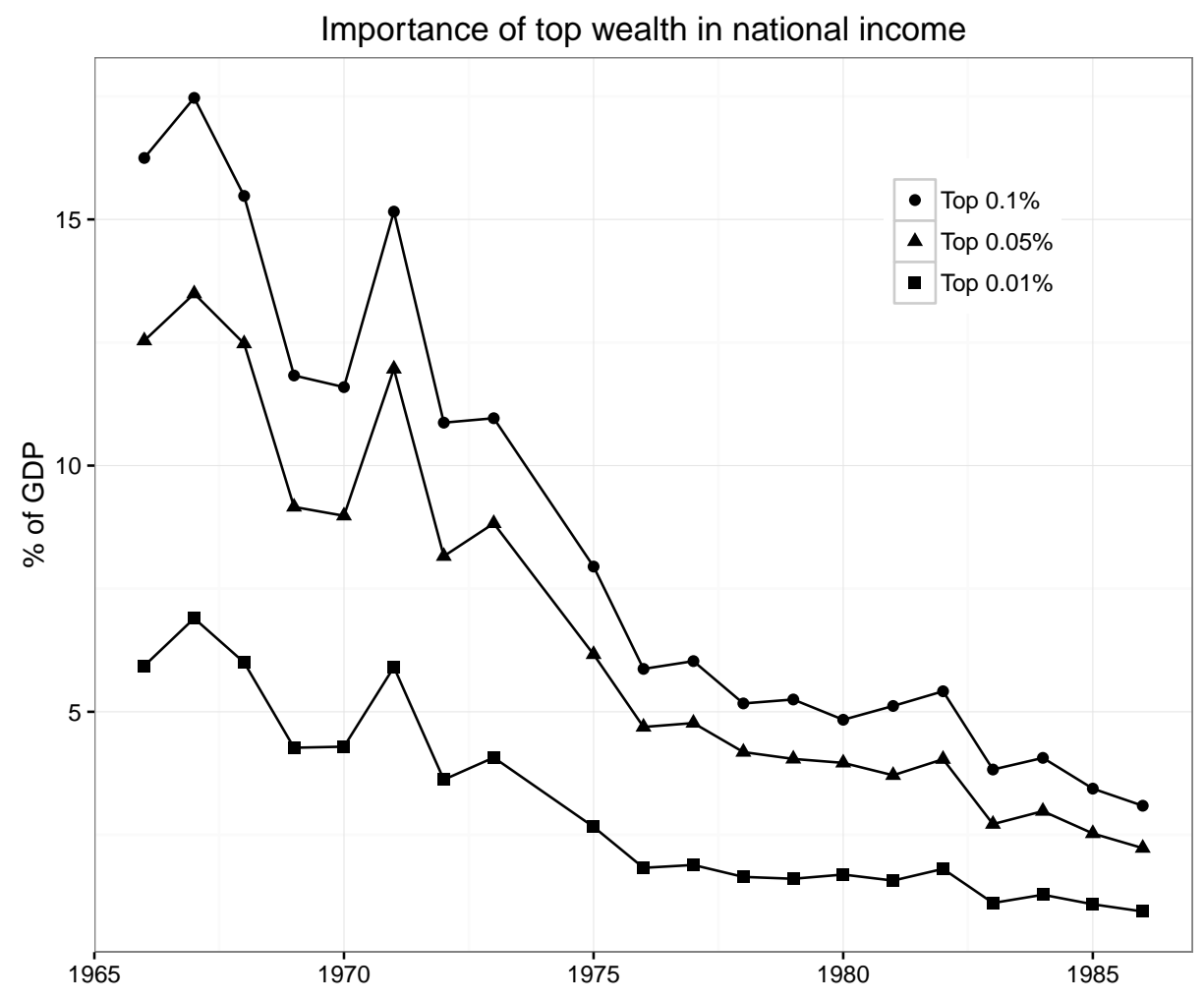

Figure 4: Author's computations

So far, the presentation is with respect to wealth amongst households and national income. To make comparisons with top incomes and households in general the next table presents shares of the top wealth holders and income earners as a proportion of total household income. Note that the total elite is the same in both cases as both are a fraction of tax units (NAS), though the actual persons involved may be different. Since household income is less than GDP, elite wealth is obviously larger as a ratio of tax unit income combined with the fact that wealth tends to be more concentrated than income. Regardless, the trends in income and wealth at the top are similar. Banerjee and Piketty (2005) estimated the share of the Top $0.1 \%$ in household income to be around 3-4\% in 1966 which declined to about $1.2 \%$ by 1980 and showed a resurgence starting 1984 with the adoption of incumbent-capital friendly policies. ${ }^{13}$ At the same time, the share of the Top 0.1\% (ranked by wealth) declined from $27 \%$ to $8 \%$ by 1980 and a further decline to $5 \%$ by 1986 . Thus from an empirical perspective, business sector reforms were able to drive a small upward trend in top incomes (through the generation of higher salaries) but the fate of the wealthy persisted throughout. The abolishment of the estate tax in 1985 could however have re-energized inheritance driven wealth accumulation again. Although we cannot extrapolate the rise in top wealth after 1986, if the subsequent rise of top income shares are any indicator then this period represents a structural break in the long run decline of the elite.

\footnotetext{
${ }^{13}$ See Rodrik and Subramanian (2005) on the transition from Hindu growth to pro-business policies in the 1980s
} 


\begin{tabular}{rrrrrr}
\hline & Year & Top 0.1\% (wealth) & Top 0.01\% (wealth) & Top 0.1\% (income) & Top 0.01\% (income) \\
\hline 6 & 1966 & 26.56 & 9.70 & 3.66 & 1.16 \\
7 & 1967 & 27.41 & 10.82 & 3.51 & 1.03 \\
8 & 1968 & 27.02 & 10.48 & 3.48 & 1.01 \\
10 & 1970 & 20.24 & 7.49 & 3.43 & 1.03 \\
11 & 1971 & 26.64 & 10.38 & 2.83 & 0.88 \\
13 & 1973 & 16.81 & 6.24 & 2.22 & 0.64 \\
14 & 1975 & 14.19 & 4.75 & 2.25 & 0.62 \\
15 & 1976 & 10.46 & 3.26 & 2.16 & 0.62 \\
16 & 1977 & 10.09 & 3.16 & 1.90 & 0.51 \\
17 & 1978 & 9.17 & 2.92 & 1.81 & 0.51 \\
18 & 1979 & 9.31 & 2.85 & 1.66 & 0.46 \\
19 & 1980 & 7.85 & 2.75 & 1.39 & 0.40 \\
20 & 1981 & 8.49 & 2.61 & 1.21 & 0.30 \\
21 & 1982 & 9.59 & 3.20 & 1.33 & 0.34 \\
22 & 1983 & 6.46 & 1.88 & 1.83 & 0.48 \\
23 & 1984 & 7.19 & 2.27 & 1.88 & 0.50 \\
24 & 1985 & 6.12 & 1.94 & 2.45 & 0.66 \\
25 & 1986 & 5.60 & 1.71 & 2.61 & 0.70 \\
\hline
\end{tabular}

Table 1: Top wealth holders and income holders expressed as shares of tax-unit income of households over 1966-1986. Data on top incomes are sourced from Banerjee and Piketty (2005)

As I have stated before, there are no reliable personal wealth measures for the entire population. However using a sample survey measure, the RBI tabulates a series on Household Capital (starting 1981, see Appendix A.2). To compare estimates, the table below presents the shares of the Top 0.1\% and Top 0.01\% in household capital over 1981-1986. Unfortunately the data restricts the formation of a longer series to compare these shares. However, these limited series reveal a possible 4-6\% share of household capital for the Top $0.1 \%$ and around $1.2-1.5 \%$ for the Top $0.01 \%$. Note that because estates vary in number over the years, taking a share of estates to total household capital would show a rise and fall of the elite depending on the number of estates filed in that year. For this reason, computing the shares of precise fractiles makes more sense. The other striking feature is that household capital over this period itself is less than $100 \%$ of GDP indicating a lack of savings to drive private wealth accumulation - a feature of capital poor nations. In rich economies, during the same period the ratio of household wealth to national income tended to be closer to $200-250 \%$ as has been shown by Piketty and Zucman (2014).

\begin{tabular}{rrrr}
\hline & Year & $\frac{\text { Top 0.1\% }}{\text { Hou Capital }}$ & $\frac{\text { Top 0.01\% }}{\text { Hou Capital }}$ \\
\hline 3 & 1981 & $6.13 \%$ & $1.88 \%$ \\
4 & 1982 & $6.10 \%$ & $2.04 \%$ \\
5 & 1983 & $4.18 \%$ & $1.22 \%$ \\
6 & 1984 & $4.72 \%$ & $1.49 \%$ \\
7 & 1985 & $3.92 \%$ & $1.24 \%$ \\
8 & 1986 & $3.41 \%$ & $1.04 \%$ \\
\hline
\end{tabular}

Table 2: Share of top wealth holders in the RBI estimates of household capital 


\subsection{Composition of wealth}

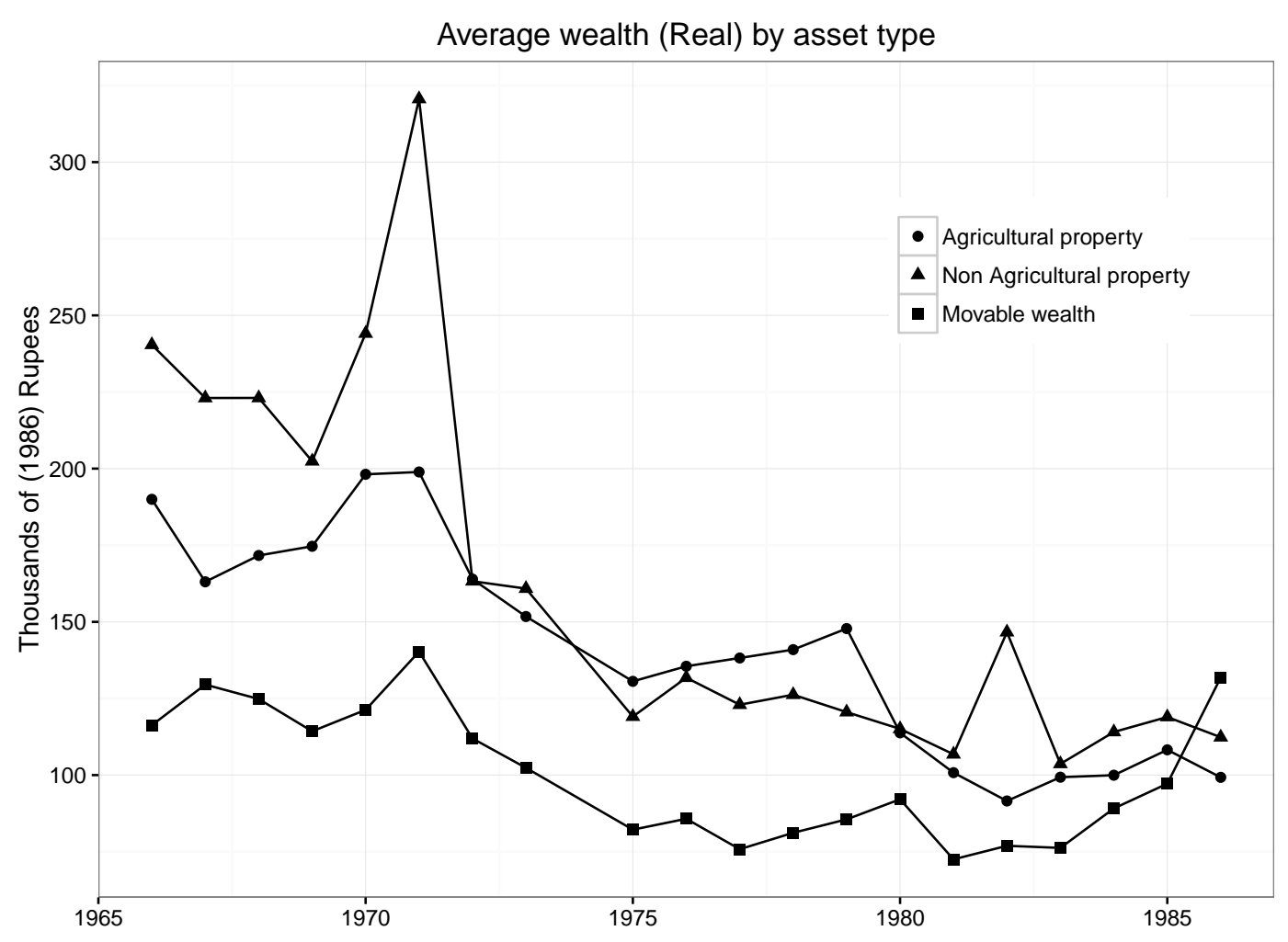

Figure 5: Author's computations

Having documented the trends in aggregate wealth, the next question is the metamorphosis of wealth (by type) over this period. Despite the advantage of having a slightly longer trend (starting 1961), the lack of microdata on personal portfolios ${ }^{14}$ means only average and total decompositions are permissible. Further, the coverage entails all tax units derived from the estate multiplier hence the decomposition of wealth of precise fractiles is not possible - a decline in total estate multiplied wealth is caused by a decline in estates above the exemption limit in later years (figure 1). The above figure shows the average (real) wealth by type of asset i.e agricultural real estate, non agricultural real estate and movable wealth. Urban real estate was throughout the most valuable asset in general although even agricultural properties were more valuable assets than movable wealth. Since the series are in constant $(1986=100)$ prices, both forms of real estate declined in value through 1961-1986 although urban real estate saw a massive surge between 1968-1971 (almost 160\%) before eventually declining. This may be both the result of an expanding urbanization and possible undervaluation of properties by the elite. On the other hand the trend in movable wealth shows a clear U shaped pattern between 1972-1986, with the average movable wealth portfolio starting at (and returning to) approximately Rs 180,000 by the end of the period. Though this maybe expected with the onset of capital friendly tax reform, the trend also reflects the fact that financial assets (particularly equity and investments) are more difficult to undervalue.

\footnotetext{
${ }^{14}$ Appendix A.1.1
} 


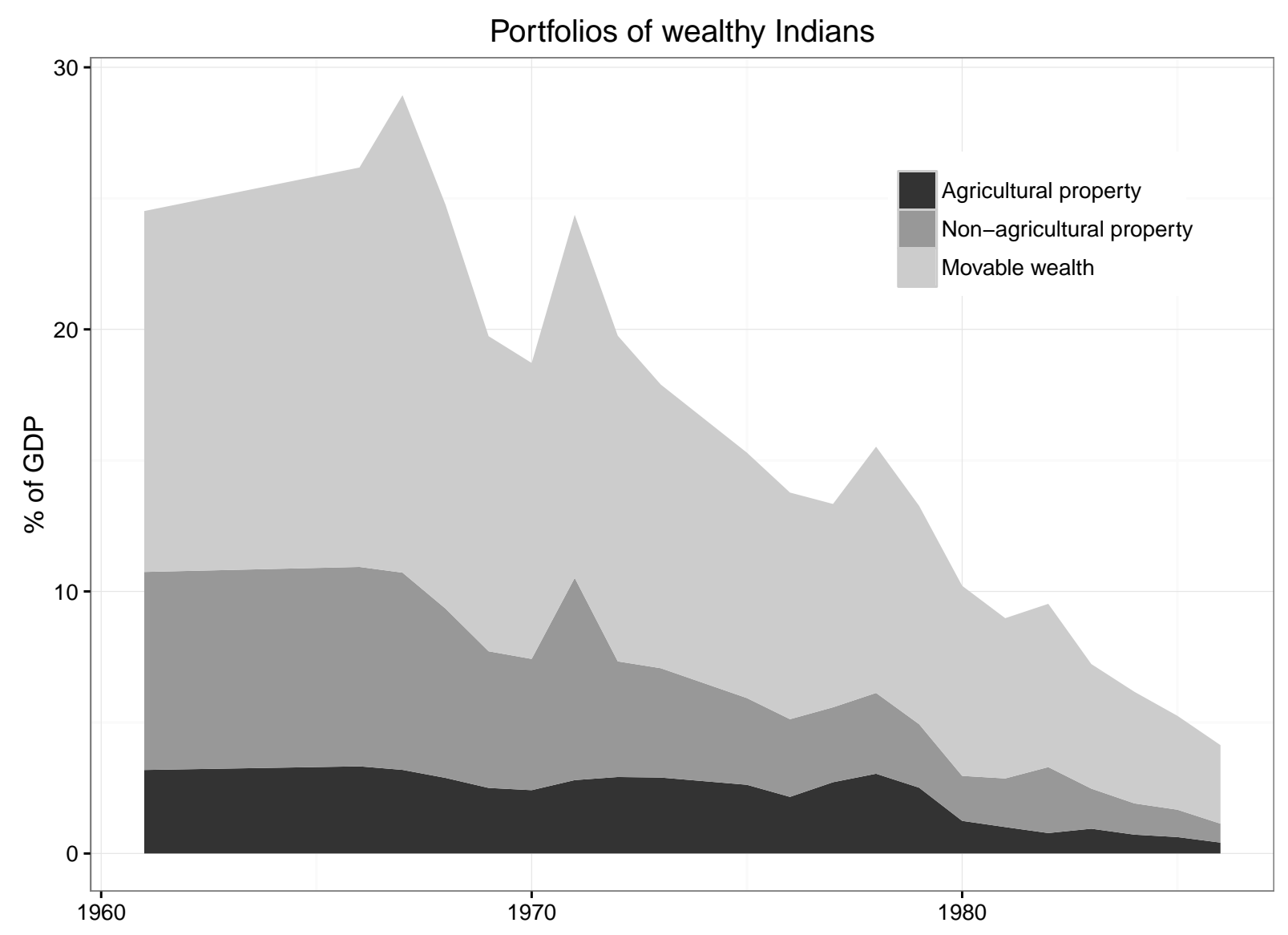

Figure 6: Author's computations

As a percentage of nominal GDP (see figure above), movable wealth constituted the largest component of aggregate elite portfolios. As a whole, wealth accumulation at the top was vastly outpaced by GDP growth in relative terms. Agricultural property fell from over 3\% in the 1960s to less than $0.5 \%$ by 1986 . This was no doubt driven by at least partially by the state-led land reforms ${ }^{15}$ whose effects took time to be realized and the fact that by the mid 1980s amendments to the Estate Tax Act led to exemption of agricultural land in a few more states (Appendix A.1.1). More condemning is the fact that movable wealth also significantly declined from a high of $18 \%$ of GDP in 1967 to just around $3.5 \%$ by 1985 . The latter, in combination with the upward trend in the average (real) value of movable wealth reflects a definite decline in the landed wealth of the rich, relative to national income.

A further decomposition of movable wealth reveals the trends within this category in terms of financial assets, business assets etc. ${ }^{16}$ The share of government securities follows a cyclical trend composing between 3-6\% of total movable assets. Secondly physical assets also increased their share, possibly driven by the $700 \%$ price increase of gold (per 10 grams) relative to CPI inflation between 1971 and 1986. ${ }^{17}$ The largest overall gain is made by the -other- category which accounts for assets which are neither immovable property nor standard definitions in movable wealth. That this is an

\footnotetext{
${ }^{15}$ Sharma (1994)

${ }^{16}$ See detailed definitions in A.1.1

${ }^{17}$ Prices as per RBI estimate of averages on Bombay markets
} 
accounted asset category in estate documents and retains a significant chunk of total elite wealth makes it interesting, particularly in 1986 when it was more than half of movable wealth. On this category, official documents and papers reveal no exact meaning.

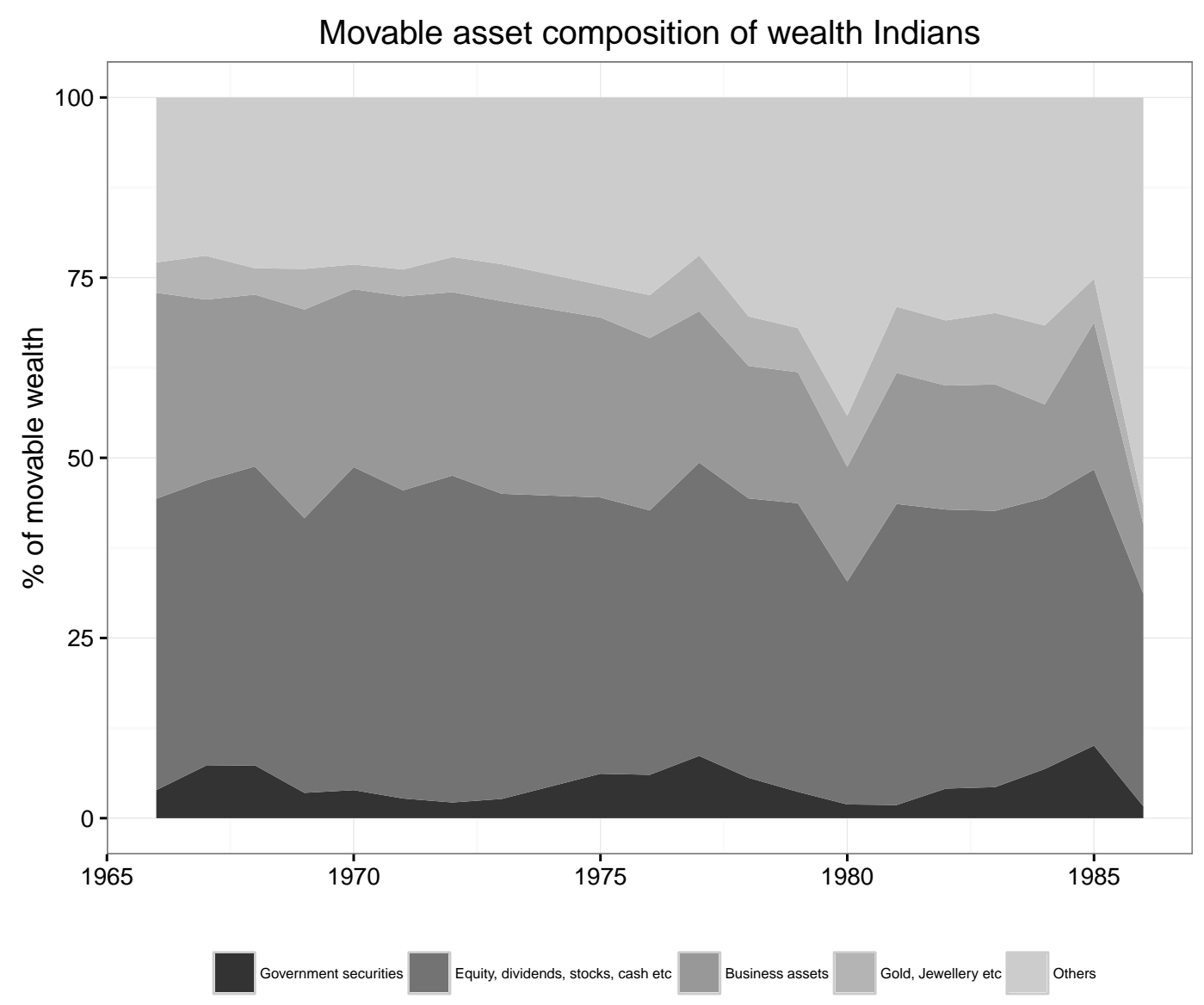

Figure 7: Author's computations

\subsection{Disparity within the elite}

So far, evidence presented has concerned elite wealth relative to aggregate flows. However another important temporal index is wealth concentration (or diffusion) within the rich themselves i.e the shape and scale of the upper tail of the Indian wealth distribution. In this case we are looking again at the entire population above the estate tax limits which fluctuates over time, but represents at the very least the Top $0.1 \%$. Typical to these upper tails of the wealth distribution is a power law of the kind originally proposed by Pareto (1964). Its most common statement, the so-called weak or asymptotic Pareto law says:

$$
C(w) \approx\left(\frac{w}{w_{0}}\right)^{-\alpha}
$$

Where $C(w)$ is the inverse cumulative distribution function (i.e the probability of some $w^{*}>w$ ), $w$ is wealth and $w_{0}$ is the least wealth level to which the Pareto law applies - in this case, the exemption limits for filing estate taxes. Low values of $\alpha$ suggest fatter tails, or more inequality within the upper tail. The cumulative distribution of estate returns exhibited a good agreement with this law ${ }^{18}$ and

\footnotetext{
${ }^{18}$ See Appendix C.1 for details and discussion of the Pareto law
} 
the resulting coefficient $(\alpha)$ can be transformed into $\phi=\frac{\alpha}{\alpha-1}$ or the inverse Pareto coefficient. This is a key property of the Pareto law and $\phi$ gives the constant ratio of the average wealth level above any threshold $w$. High values of $\phi$ (typically between 1.8 to 2.2 in rich countries) imply higher wealth concentration at the top. Figure 8 below shows the temporal evolution of $\phi$ between 1966 to 1986 . In the late $1960 \mathrm{~s}, \phi$ was more unstable and reached a high of over 3.3 in 1968. Its value stabilized around 2 in the $1970 \mathrm{~s}$ and then showed a slight increase to 2.5 by 1986 . Put simply, wealth was very concentrated even amongst the elite at the start of the period of study but disparity reduced until the end of the 1970s after which it again began to expand. Given the rise of movable wealth, this points to a potentially higher rate of return to financial portfolios and coincides with a series of reforms with regard to capital gains taxation starting in the late 1970s. ${ }^{19}$

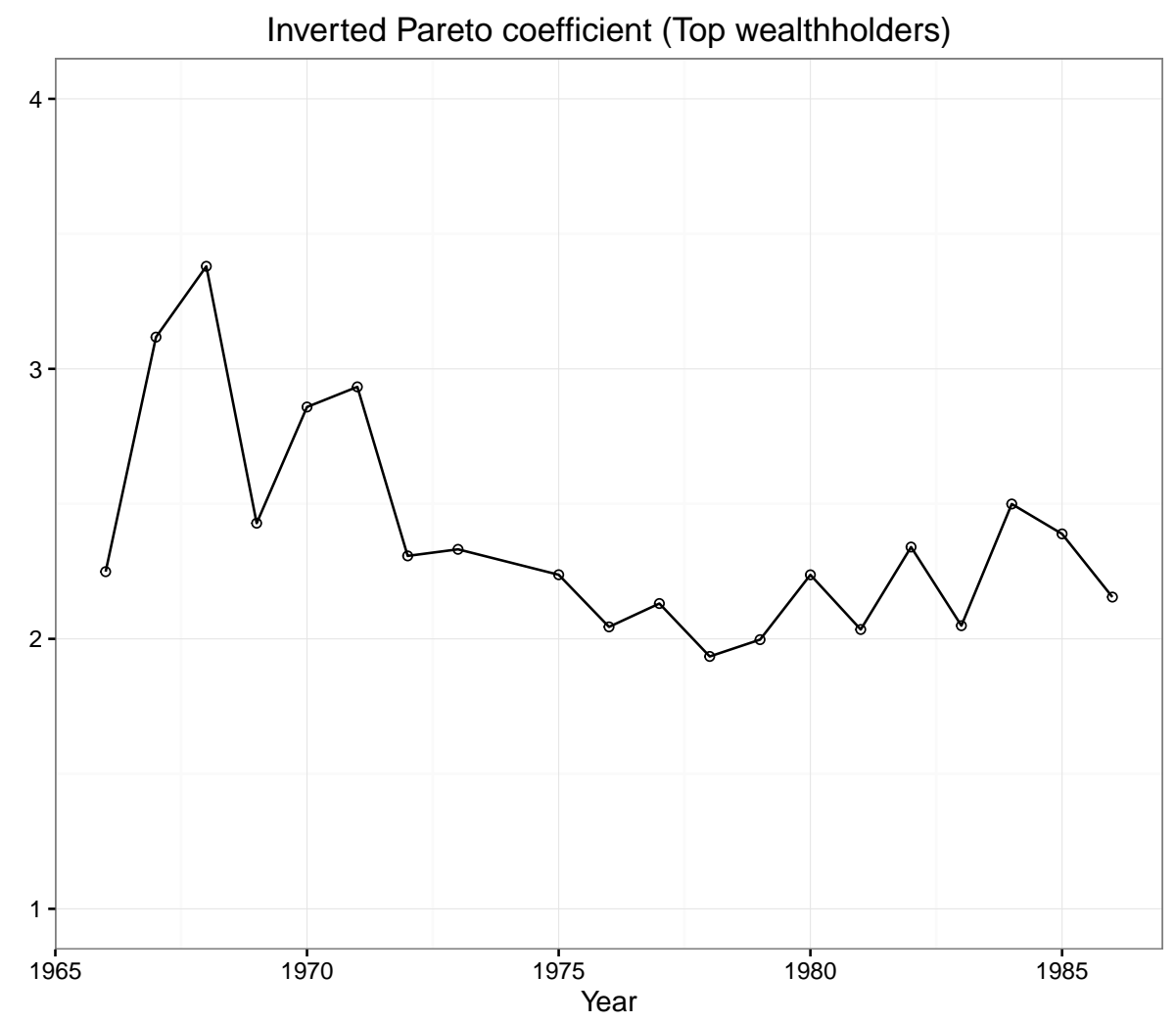

Figure 8: Author's computations of estate tax data

At the same time, taking a ratio of the wealth of the super-elite (the Top $0.01 \%$ ) amongst the Top $0.1 \%$ can shed more light on wealth activity within the elite. The figure below reveals that much of the decline in top wealth shares was driven by a fall of the super elite. The Top 0.01\% owned around 37-38\% of total wealth amongst the Top 0.1\% until 1972. Barring momentary jumps in 1973 and 1980, there was a slow decline down to around 31-32\% by the mid 1980s. Suppose we consider these three partially overlapping groups - The Top $0.1 \%$ (elite), those above the Top $0.1 \%$ threshold and below the Top $0.01 \%$ threshold (the intermediate elite) and finally the Top $0.01 \%$ (the super elite). A combination of the inverse Pareto coefficient and the share of the Top $0.01 \%$ thus implies that wealth concentration, even within the elite was at its peak until 1972. There onwards, the super elite lost their share and the steady fattening of the Pareto distribution over 1978-1986 was

\footnotetext{
${ }^{19}$ See appraisal and criticisms of various pro-rich direct tax measures for 1985-86, previous budgets and other reforms in Kumar (1985)
} 
potentially driven by more disparity within the 99.9 - 99.99th percentiles - the intermediate elite. An educated guess would then point to two related trends. The decline in the average value of landed properties probably affected the super elite (likely the landed gentry) the most. The increase in wealth inequality within the intermediate elite was a result of the rise in the real value of movable assets where new entrants could emerge from good investments in financial markets, especially after the tax break on capital gains through the 1977 Finance Bill. This picture could be confirmed were there detailed information of the distribution of assets within this group, but a further investigation of this hypothesis will follow in the next section.

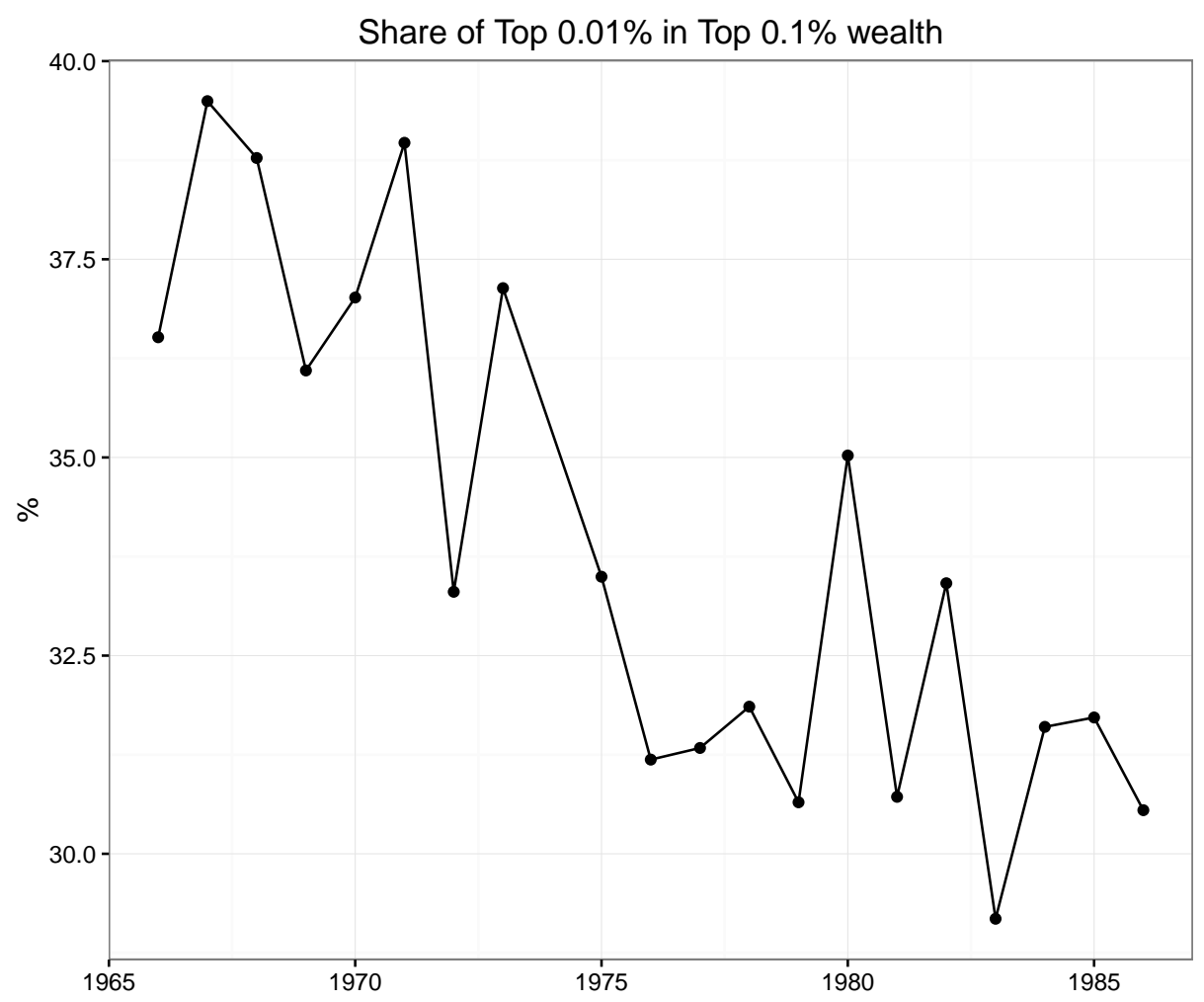

Figure 9: Author's computations of estate tax data

\section{Discussion}

The table below summarizes the previous findings as different rates through the Hindu growth period. Between 1966-1972, GDP growth outpaced household income in real terms, while the wealth of the elite was shrinking. In the next period (1973-1979) there was a 10\% contraction of real super elite wealth and thus had a huge impact of the elite wealth - GDP ratio. The 1979-1986 period continued the trend in negative growth of elite wealth this rate was at its lowest level in historical terms. The decline in real wealth for the intermediate fractile (99.9-99.99) was actually only about $1.2 \%$. In general, the losses borne by the Top $0.01 \%$ were the most excessive. While accumulation was low, no doubt encouraged by the very high progressive taxes on capital and capital income, cost price inflation played a big role. The progressive rise in long term inflation peaked at almost $10 \%$ during the 1980-1986 period.

On the face of it, what stands out is that even the modest rate of economic growth was able 


\begin{tabular}{rrrrrrr}
\hline & Year & GDP (real) & Household income (real) & Top 0.1\% (real) & Top 0.01\% (real) & CPI inflation \\
\hline 1 & $1966-1972$ & $4.58 \%$ & $3.72 \%$ & $-2.54 \%$ & $-4.49 \%$ & $5.37 \%$ \\
2 & $1973-1979$ & $5.47 \%$ & $2.77 \%$ & $-7.54 \%$ & $-10.67 \%$ & $7.15 \%$ \\
3 & $1980-1985$ & $5.51 \%$ & $3.42 \%$ & $-2.10 \%$ & $-8.83 \%$ & $9.83 \%$ \\
\hline
\end{tabular}

Table 3: Real growth rates of income and wealth through 1966-1986. All nominal values deflated with CPI inflation $(1986=100)$

to outperform personal wealth accumulation in line with the goals of social equity. But with these remarkable statistics at hand, there are in principle at at least two important questions to be answered in this section. Firstly, was there really a decline in wealth as opposed to a significant under-reporting of assets for the purposes of tax evasion? ${ }^{20}$ Second, if there was indeed a decline then what possible factors and policies could have caused the steep decline of the elite and super elite classes?

\subsection{Adjusting for undervaluation and tax evasion}

The perennial problem with undocumented wealth in India, as I have discussed previously is the high proportion of undervalued real estate. This was most rampant in the real estate sector ${ }^{21}$ where large volumes of capital gains could be realized through under-the-table transactions. From the perspective of accumulation, this is characteristic of inefficiencies in the institutional arrangement between the regulating body (tax authorities) and the market. In developing economies with incomplete contracting this can be a principle source of accumulation amongst the propertied elite i.e capital in pursuit of higher effective rates of return tries to move into under-regulated sectors and undocumented capital gains above the regulated price go completely undetected.

In the simplest example, consider a one good model of accumulation with a fixed asset (such as real estate) and hence no savings. Suppose the market value of the asset is $k_{t}=\left(1+\delta_{t}\right) L$, where $L$ is the value of the asset disclosed to authorities and $\delta_{t}$ is the additional undervaluation factor. ${ }^{22}$ Further suppose there is no growth in the disclosed price over a period of time and there is positive economic growth $n$. In such a scenario, at equilibrium $(\hat{k}=n>0)$ accumulation is entirely absorbed by unreported capital gains from which naturally no revenue is collected. Thus parallel to the actual economy, hidden wealth arises from undocumented capital gains but there is no accumulation on paper, to avail itself to tax authorities. This was a frequent concern of Indian policy makers and various laws were passed to acquire properties when there was evidence of significant undervaluation. ${ }^{23}$ Appendix D addresses this issue in more detail and outlines the methods I have used to deal with this problem.

As a counterfactual exercise, using estimates from the real estate market in Delhi from 1979-1986, I have constructed inflation factors on non-agricultural immovable property (or urban real estate) to uncover any undervaluation bias. The figure below shows the result of this exercise. Measure 1 and 2 signify real estate inflation factors from two samples that Acharya (1986) estimated (see Appendix D). Due to the limited sample size and assumptions involved, these estimates should be taken with a grain of salt. The consequence of this exercise however is that while the value of

\footnotetext{
${ }^{20}$ In 1971, the Wanchoo Direct Taxes Enquiry Committee put out a report recognizing the rationality of evading the super-progressive tax structure. See Acharya (2005) on direct taxation before the first wave of reforms.

${ }^{21}$ See Acharya (1986) on the various vehicles for tax evasion used in India

${ }^{22}$ This basically means the additional black or unreported value

${ }^{23}$ The effectiveness of these laws remained questionable. See Kumar (1985)
} 
properties significantly appreciates, its importance as a ratio of GDP continues to carry the original downward trend. The appendix carries nominal value estimates of the size of urban which increase on average by about 100\% (Measure 2) to 200\% (Measure 1). The figure below shows the at the decline in urban real estate using Measure 1 was still quite strong by 1985 (about 3\%) from a high of $10 \%$ in the late 1970s. Since this measurement uses total estate wealth which declined as the number of estates above the exemption limit fell over time, the downward trend is partially misleading - real estate (urban) inflated for undervaluation becomes a large proportion of wealth but is regardless outpaced by the growth of financial, business and other movable assets held by the elite. At no point did the undervaluation adjusted measures of real estate ever exceed $40 \%$ of total wealth. The wealth components of the top fractiles are not visible but since they comprise a share of total estate wealth, there is no doubt that the declining ratio of their wealth to GDP would continue to hold after adjustments on urban real estate.

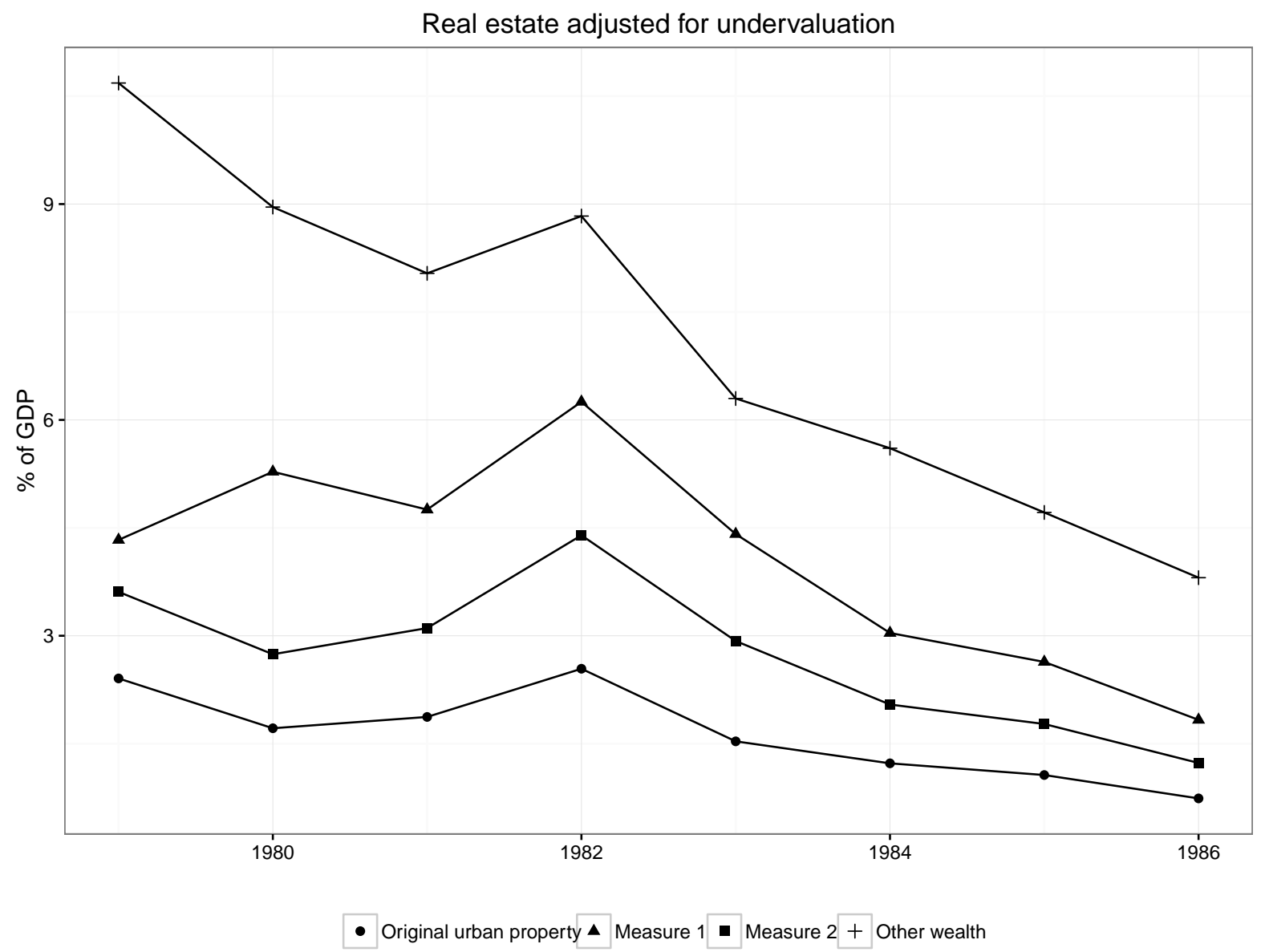

Figure 10: Author's computations of estate tax data and estimates in Acharya (1986). Measure 1 and 2 correspond to Broker and IT sample. Original urban property refers to non-agricultural immovable estate wealth

\subsection{A real decline of wealth?}

Controlling for undervaluation does not provide a satisfactory answer to the decline of the wealthy over 1961-1986. Further the decline in the Top 0.1\% happened around the same time as the decline of the shares of top income earners as estimated by Banerjee and Piketty (2005). We must contend 
with the possibility that a combination of policies and shocks put in place by the various governments played a real role in the slowdown and subsequent decline of rich Indians. To assess the trends, one useful mode of analysis is the evolution of the inverted Pareto coefficient which I have previously presented. The rationalization of this index in economic theory is usually attributed to dynastic models of primogeniture ${ }^{24}$ or multiplicative shocks ${ }^{25}$ such as a poor set of investments, policy measures or differential rates of return. However the applicability of these models is over the very long run, or at least over a few lifecycles to sufficiently swell or shrink the Pareto coefficient. In the case of the Indian data, the period of analysis is just about one lifecycle (or 25 years).

An alternate model of the evolution of the Pareto coefficient is the class of statistical equilibrium models, developed originally by Foley (1994). These models propose that the statistical equilibrium (or maximum entropy ${ }^{26}$ distribution) outcome, i.e the macrostate which corresponds to the largest number of microstates, is a plausible explanation of decentralized activity among a large number of agents. An application to wealth portfolios of the wealthiest Americans using Forbes magazine data is done in Castaldi and Milaković (2007). Since we do not possess microdata on the exact fate of each portfolio, statistical equilibrium reasoning serves as a useful conceptual instrument applied to the fractiles as a whole. The authors (ibid) derive the Pareto coefficient using this model of wealth portfolios $^{27}$ The statistical equilibrium Pareto coefficient $\alpha^{*}$ is inversely related to the average rate of turnovers $(\tau)$ or changes in the portfolio composition per unit of time. Hence higher turnover activity such as shifting weights and investments within the portfolio results in lower values of $\alpha^{*}$ - or a fatter tail. In a simple way, this signifies that deregulation of financial activity, increased capital flows and greater investment opportunities can increase the degree of wealth concentration in probabilistic terms. The upshot is that as controls over equity and capital markets are lifted, the degree of wealth concentration increases which is fairly consistent with the findings of Piketty (2014) for the United States since the middle of the the 20th Century.

\subsubsection{Evolution of state policy towards the elite}

Immediately after independence the Indian administration put in place a whole range of regulations to tax the wealthy and socialize investment. The Nehruvian socialist impetus was to channel the surplus for the accumulation of national capital and spur economic growth - thus capital accumulation was a centralized and planned activity. Whether these measures succeeded in spurring growth is not as important for our purpose as the measures themselves. From the perspective of competitiveness and avenues for entrepreneurial investment, India's growth performance during this period has been severely criticized by development economists and authors attribute this to the set of controls during the mixed economy phase. ${ }^{28}$ The term license raj is commonly used to describe bureaucratic hurdles necessary for businesses to overcome in order to be successful during this phase. The evolution of the inverted Pareto coefficient $(\phi)$ can be analyzed using state led regulation and controls as an indicator

\footnotetext{
${ }^{24}$ An example of neoclassical growth and distribution with primogeniture is available in Stiglitz (1969)

${ }^{25}$ See for example Piketty and Zucman (2015)

${ }^{26}$ Entropy $(H)$ is defined as $-\sum_{i} p_{i} \log p_{i}$ with $\sum_{i} p_{i}=1$ where $p$ is a probability field over $i$ activities of the variable $x$. The maximum entropy distribution $p^{*}(x)$ is the solution that maximizes $H$ subject to constraints on the moments of the distribution. These constraints usually come from theoretical hypotheses such as (for example) the average number of transactions or the mean rate of return

${ }^{27}$ The Pareto distribution is the maximum entropy distribution when the constraint is the expected value of the logarithm of the distributed variable. In the case of Castaldi and Milaković (2007), the variable (wealth) is a portfolio of different economic activities such as deposits, housing, pensions, life insurance plans, financial assets etc.

${ }^{28}$ Rodrik and Subramanian (2005) review the growth performance and the degree of regulation during this period. A comprehensive criticism of tax policy and reform appraisal is done Acharya (2005)
} 
for relatively centralized turnover activity $\tau$, with $\phi$ directly proportional to $\tau$ and high regulation implying lower turnover activity. The trends in $\phi$ already presented show a very high value in the 1960s, followed by a sharp decline during the 1970s and then a slow and steady resurgence starting in the 1980s.

By the mid 1960s, personal wealth was already aggressively taxed (Appendix A) using wealth, gift and estate taxation. The direct tax structure was so aggressively progressive at the top tax slabs that it was deemed confiscatory by public finance expert in retrospect. Additionally, a series of land reforms were and ceilings on holdings were carried out ${ }^{29}$ to create social equity in rural India, one of the stated aims of the Indian Congress party which was in power for most of this period. These measures were particularly successful in the states of West Bengal and Kerala and by 197071, the feudal arrangements of agricultural land had been revolutionized. The targeted national accumulation path was a vision of Jawaharlal Nehru, who passed away in 1964 and was succeeded as Prime Minister by his daughter Indira Gandhi (Gandhi I) in 1966. Her initial realm was at least projected to be aggressively pro-poor and geared towards strongly regulating private capital. She made it clear in her budget speeches that the equalization of wealth and incomes should be achieved using taxes as an instrument. ${ }^{30}$ To curb speculative activities on financial markets further, in 1972 the capital gains tax was raised to its highest historical level. However, the wealthy incumbents of the nation retained control in other spheres of the economy, such as banking and coal.

To this end, she (Gandhi I) instituted at least three major reforms which were to contribute to the dramatic decline in private wealth over the 1970s. Firstly, 14 private banks were nationalized into the public sector under the 1970 Banking Companies (acquisition and transfer of undertakings) act. This not only meant a loss of control amongst the management elite in these banks but also added layers of bureaucracy to banking norms thereby regulating the sector even further. Now serving as public banks, the investment portfolios of these institutions were regulated in line with priority lending norms and very strong capital controls. Secondly between 1971 and 1973, private coal mines in Eastern India were nationalized ${ }^{31}$ and turned into Public Sector Undertakings (PSUs). The impact of this was particularly severe as coal dynasties had been a source of ancestral private capital in this region since before independence and henceforth became centralized state assets. Finally the noble gentry were also targeted with the abolition of the Privy Purse in 1971 which used to entail a series of very handsome payments and privileges made to the princely class for their assistance in Indian integration. Whether this policy was demonstrative or not, how the legal architecture also became embroiled in economic policy and the backdrop of the necessary constitutional amendments is discussed in Roberts (1972). Thus the 1970s in historical perspective could be deemed as anti-elite from the policy viewpoint. Large inflation shocks from the global oil crisis of 1973 and 1979 further contributed to the erosion of real private wealth. The nature of such shocks was to cause spikes in inflation and then a quick state redressal to control it because price rise was always a grave political issue. $^{32} 33$

\footnotetext{
${ }^{29}$ See the review of Indian land reforms, their history and impact in Sharma (1994)

${ }^{30}$ See Acharya (2005)

${ }^{31}$ See Kumar (1981) on the nationalization of private coal

${ }^{32}$ For a review of this inflationary period and the political economy of macroeconomic management see Joshi and Little (1994)

${ }^{33}$ Not mentioned here is the declaration of emergency between 1975-77 and the official adoption of socialism through constitutional amendment, though the exact impact on the elite is not clear.
} 
After years of slow (or Hindu) growth and opposition pressure Gandhi started lifting regulations starting in 1980, in what was termed Operation Foward. Rodrik and Subramanian (2005) trace the attitudinal shift in the administration as the core reason for the emergence from the low rates of growth in the preceding decades. The authors (ibid) claim the liberalization of capital regulations started by Gandhi I and fast-tracked by her successor Rajiv Gandhi (Gandhi II) led to a better investment climate which benefitted existing big businesses (rather than attracting international capital). Wealth and income tax rate reductions started with the budgets of the late 1970s but by 1978 (through the Finance Bill of 1977) the administration had relaxed taxes on capital gains entirely as long as the proceed of asset sales were invested in certain securities. The steady release of regulation controls in state policy coincides with the rise of the inverted Pareto coefficient $(\phi)$ in elite wealth and faster income growth. This indicator $(\phi)$ also follows the $\mathrm{U}$ shaped trend in the average (real) value of movable assets such as financial and government securities, insurance, gold etc. Land transactions are slower to materialize but financial assets can be traded much more rapidly. From the perspective of the turnover indicator of Castaldi and Milaković (2007) the upward trend in $\phi$ was driven by increased decentralization in the turnover activity of these asset classes. Since the real average value of these assets was rising, this indicates that such transactions were able to beat CPI inflation and those who transacted in these markets were likely to outgrow (in terms of portfolio returns) the landed gentry. Thus the more dramatic fall of the Top $0.01 \%$ relative to the Top $0.1 \%$ further points to a decline of the ancestrally wealthy and a rise of a more financially savvy wealth class. These liberalization reforms were geared towards the generation of manufacturing and service sector employment and so there was a wage-led rise in household income followed by a rise of top Indian incomes in Banerjee and Piketty (2005). The significance of these reforms, at least for inheritance, was magnified in 1985, when the estate tax was abolished and it would not be a surprise if this would have served as a trigger for a reversal in the fortunes of the elite. By its very nature wealth accumulates over time, hence it would take longer for my top wealth measures to rebound and for years following 1986 such data is not available.

\section{Conclusion}

My conclusions are brief. This paper has presented and analyzed the first series on top wealth holders for India. The Indian economy was constrained by a lack of capital in the 1960s and so those who were already very wealthy controlled a significant amount of wealth. For the state apparatus which had limited the flow of foreign capital into the economy, taxation of such wealth was a priority for revenue collection and equalizing social and economic disparity. The former objective was never really fulfilled ${ }^{34}$ but the evidence in this paper suggests that the attack on the elite initiated the over 1966-1972 did partially achieve the latter aim - the super elite declined in importance. Public policy developments coincide with the patterns of top wealth shares and the Pareto coefficient. By dis-incentivizing wealth accumulation through both policy measures and signal of intent, Gandhi I exerted a squeeze on private capital and restricted the space for it to realize returns, which led to the decline of top Indian wealth holders. The counterfactual exercises indicate that though wealth may have been hidden through undervaluation and tax evasion, the impact of policy was still strong enough to justify the estimates of this paper - state measures strongly affected the wealthy. With extended data it would be more clear whether the decline of the Top 0.1\% started with Gandhi I or in previous periods. There is a chance that the aim to build national capital, starting with the second five year plan in 1956 could very well have crowded out personal capital in importance. The era in question (particularly because growth was very modest) serves as a fairly significant counterexample

\footnotetext{
${ }^{34}$ See Rao et al. (2006) and Acharya (2005)
} 
to the cases documented in Piketty (2014) where low growth in rich countries leads to a rise in wealth accumulation and concentration due to the importance of past savings.

\section{References}

Acharya, S. (1986): Aspects of the Black Economy in India: Report Submitted to the Ministry of Finance, Government of India, Ministry of Finance.

(2005): "Thirty years of tax reform in India," Economic and Political Weekly, 2061-2070.

Atkinson, A. B. And A. J. Harrison (1978): Distribution of personal wealth in Britain, Cambridge University Press.

BAGCHI, A. (1974): "Redistributive role of taxation in India: an appraisal," Poverty and Income Distribution in India, 441-465.

BanerJee, A. And T. Piketty (2005): "Top Indian Incomes, 1922-2000," The World Bank Economic Review, 19, 1-20.

Castaldi, C. And M. Milaković (2007): "Turnover activity in wealth portfolios," Journal of Economic Behavior \& Organization, 63, 537-552.

Deininger, K., A. Goyal, And H. Nagarajan (2013): "Women's inheritance rights and intergenerational transmission of resources in India," Journal of Human Resources, 48, 114-141.

Dyson, T. And M. Moore (1983): "On kinship structure, female autonomy, and demographic behavior in India," Population and Development Review, 35-60.

Foley, D. K. (1994): "A statistical equilibrium theory of markets," Journal of Economic Theory, $62,321-345$.

Goldsmith, R. W. (1983): The Financial Development of India, 1860-1977, Oxford University Press.

Joshi, J. And L. Venkataraman (1980): "Mortality of Indian Assured Lives," Economic and Political Weekly, M101-M106.

Joshi, V. And I. M. D. Little (1994): India: Macroeconomics and political economy, 1964-1991, World Bank Publications.

KALDOR, N. (1956): Indian tax reform: report of a survey, Ministry of Finance, Department. of Economic Affairs.

- (1959): "Tax Reform in India," Economic Weekly, 15, 195-98.

Kopczuk, W. And E. SAEz (2004): "Top Wealth Shares in the United States, 1916-2000: Evidence from Estate Tax Returns," National Tax Journal, 445-487.

Kumar, A. (1985): "Union Budget, 1985-86: Haves Have while Have-Nots Nought," Economic and Political Weekly, 717-721.

(2002): The Black Economy in India, Penguin Books India. 
Kumar, R. (1981): "Nationalisation by default: The case of coal in India," Economic and political weekly, 757-768.

LAmpman, R. J. (1962): "The share of top wealth-holders in national wealth, 1922-56," NBER Books.

Pareto, V. (1964): Cours d'économie politique, vol. 1, Librairie Droz.

Patel, I. (1986): "Free enterprise in the Nehru era," in Essays in Economic Policy and Economic Growth, Springer, 165-181.

Piketty, T. (2014): Capital in the 21st Century, Harvard University Press.

Piketty, T., G. Postel-Vinay, and J.-L. Rosenthal (2006): "Wealth concentration in a developing economy: Paris and France, 1807-1994," The American Economic Review, 96, 236256.

Piketty, T. And G. Zucman (2014): "Capital is back: Wealth-income ratios in rich countries, 1700-2010," The Quarterly Journal of Economics. 2.

RAO, M. G., R. K. RAO, ET AL. (2006): "Trends and issues in tax policy and reform in India," in India Policy Forum, National Council of Applied Economic Research, vol. 2, 55-122.

Roberts, N. A. (1972): "The Supreme Court in a Developing Society: Progressive or Reactionary Force? A Study of the Privy Purse Case in India," The American Journal of Comparative Law, $79-110$.

Rodrik, D. And A. Subramanian (2005): "From Hindu growth to productivity surge: the mystery of the Indian growth transition," IMF Staff Papers, 52, 193-228.

Sharma, H. (1994): "Distribution of landholdings in rural India, 1953-54 to 1981-82: Implications for land reforms," Economic and Political weekly, A12-A25.

SinHA, S. (2006): "Evidence for power-law tail of the wealth distribution in India," Physica A: Statistical Mechanics and its Applications, 359, 555-562.

Srinivasan, T. N. (1973): "Tax evasion: A model," Journal of Public Economics, 2, 339-346.

Stiglitz, J. E. (1969): "Distribution of income and wealth among individuals," Econometrica: Journal of the Econometric Society, 382-397.

\section{Appendices}

\section{A Data sources}

Comprehensive and consistent estimates of wealth for India are scarce and no micro-data were computerized prior to 1991-92. The various rounds of the National Sample Survey Organization (NSSO) 
do publish an asset survey every decade, but the shortcomings of topcoded surveys combined with non-response at the top makes these inappropriate to capture the super rich. In fact the core idea of this survey is capture levels of debt amongst the impoverished masses. The primary datasource used throughout this paper is the All India Wealth tax, Gift tax and Estate duty statistics, published by the Indian Tax authorities on an annual basis. These reports compile and preprocess data from the Central Board of Direct Taxation (CBDT) for their various personal wealth taxation schemes.

Unlike many rich countries, the Indian administration had instituted a wealth tax (Wealth Tax Act of 1957) which acted as a wealth census of tax units such as Individuals, Hindu Undivided Families (HUF) and even Companies. In keeping with a stance on progressive taxation, originating from the Kaldor Committee Report, marginal rates were extremely high and tax evasion became a frequent problem. Ironically, the case for the wealth tax was itself proposed by Kaldor (1959) to overcome tax evasion in expenditure taxes. Acharya (2005) summarizes a history of the effectively confiscatory rates of direct taxation through to VP Singh's 1985-87 reforms. Rao et al. (2006) make a case for the high effective return on direct tax evasion, due to low detection probabilities. A fundamental problem with recurring wealth taxation is that although it is levied on capital assets, its payment will need to come from income (unless the asset is sold during the tax year). In many cases it may be possible to pay such taxes out of capital income, rents etc. But for persons holding unproductive assets such as vacant and unused land or inventory, tax payment may need to be come from wage income. In such circumstances, effective taxation of income may become exceedingly high and provide incentives to evade declaration of total assets. Further, a number of loopholes existed with regard to the demarcation of ancestral property between joint families and individuals. Thus the coverage of tax units was low to begin with and the statistics are either not reliable or too scant to cover a significant number of tax units. These factors in combination with the changing norms on wealth tax exemption levels through to 1992 (when this Act was heavily diluted) made it suboptimal as a source of personal wealth data.

\section{A.1 Estate data}

The Estate Duty Act of 1953 was instituted to levy a tax on the estate of decedents and it stayed in place until 1985 when an act of Parliament was created to dissolve it. The main advantage of using this measure is that while still liable to tax evasion, registration of property proceeds amongst the inheriting party would be necessary. Especially amongst the wealthy who may want to leave bequests, the receiving party whether by legal wills or other instruments would need to report the estate. One way of avoiding a taxation on inheritance would be the transfer of assets as gifts, though the administration had put in place an inter-vivos gift tax starting 1958 to check such activities. In the case of financial instruments and real estate, there is no simple way to evade estate duty and paper trails. Certain items such as cash (not in banks), furniture, art etc can be transferred without registration and this remains a shortcoming of both this paper and the efficacy of the Estate Duty Act itself. The latter point is beyond the scope of this paper.

Data used in this paper relies on the assessments within this Act, as reported in the All India Wealth Tax, Gift Tax and Estate Duty Statistics. The periodic coverage range from 1961-1986, excluding 1974 when there was no publication. For the specified period, we have time series on total estates, estate valuation and details regarding the breakdown of the estate by categories (movable, immovable property). Although estate duty statistics were produced until 1990, the validity of this data after 1986 (last applicable year of the Estate Duty Act) is circumspect. A noticeable and 
expected drop in total estates follows from 1987 onwards, with the likelihood that these statistics cater to previously incomplete cases.

For the year 1966-1986 (excluding 1974) there is detailed tabulation of estates under various tax brackets including total size of the estate, number of assessments and tax unit category (Joint Hindu family and Others). The aggregated time series on estates start from 1961 (with 1962-1965 missing) but for this year, we do not have detailed tabulation statistics and only a breakdown of average estate values in agricultural property, non agricultural property and movable wealth.

\section{A.1.1 Concepts, classifications and definitions}

The Indian tax authorities compute a principle (net) estate value after deductions on gross estate. I have used exact definitions of principal estate value for my definitions of wealth. As per the Estate Duty Act (1953) the definition of property of the decedents comprise any property (movable and immovable) which can be used for sale or further investments. Various legislative amendments between 1958 and 1984 were passed to exempt agricultural lands situated in specific territories. Agricultural lands in the states of Jammu \& Kashmir and West Bengal have been exempt from estate duty since 1954. The Estate Duty (amendment) Act of 1984 exempted agricultural land in Andhra Pradesh, Karnataka and Manipur as well.

Since rebates and other schemes may offer some leeway to the total estate, all estimates in this paper are pre-tax. The unit classification of estates is done on the basis of one of two tax categories - Joint Hindu Family or Other Kind. I use in this paper, the consolidated sum across these two tax units for all categories of property classifications and this acts as my tax unit for the estate multiplier. The preprocessed tables in the estate duty reports list the composition of estates into movable and immovable (agricultural, non agricultural) properties with total estates listed under each category. Since we do not have a simultaneous breakdown of estates by size, frequency and composition, these breakdowns are used to simply compute average values of properties by type. This paper has presented an Estate Composition-GDP ratio which sums up the various property types and uses the nominal GDP measure as a denominator. Were detailed breakdowns available, a further decomposition of the top few fractiles could have been made listing the changes (if any) in asset composition going up the wealth ranking.

A further decomposition of movable wealth is also available with movable wealth split into nine categories and listed as either domestic or foreign. After consolidating the location of these assets, I have compressed these categories into five for simplicity. The definitions are as follows:

1. Government securities: Same classification

2. Equity, dividends, stocks, cash etc: Summation of Stocks, Shares \& Debentures with Cash (including fixed deposits), Life Insurance Proceeds and Slice of the assets of controlled companies.

3. Business assets: Business assets (including share in partnership and goodwill)

4. Gold, Jewelry etc: Summation of Precious stones, jewelry \& Works of Art and Household goods, vehicles, furniture etc. 


\section{A.2 Data on aggregate flows, population and inflation}

- Data on historical GDP series (annual estimate, current prices) for India have been extracted from the Reserve Bank of India (RBI) database on the Indian economy (dbie.rbi.org.in) which is itself sourced from the Central Statistics Office (CSO). I use Gross Domestic Product at Market Prices for the entire period 1961-1986. The Household Capital series from 1981-1986 is also sourced from the RBI database.

- As a control unit for total population, I have directly used -Number of tax units- from the World Wealth and Income Database (WWID). The same population unit is utilized in Banerjee and Piketty (2005) to compute top income shares. In the case of estates, since Indian tax authorities classify estates under two tax units (Joint Hindu Family and Others), this control total is the most appropriate denominator to compute population shares of the rich.

- To measure constant price GDP and other flows, the RBI also lists various GDP deflators. However to make consistent comparisons, all nominal flows have been deflated by the Consumer Price Index (CPI) historical series also sourced from WWID for 1986 (i.e $1986=100$ ).

- Asset prices for Gold and Silver are sourced from the RBI with historical series on average prices (annual, Mumbai market) from 1971 to 1986. Gold is measured in Rupees per $10 \mathrm{gm}$ and Silver in Rupees per kg.

\section{B Estate multiplier}

Estate duty statistics represent the most detailed data to estimate the size and distribution of the wealthy in India. While British studies in the early 20th century initiated this method, the first time series using this method can be traced to Lampman (1962), who made estimates of top wealth holders in the US. The core idea of the estate multiplier model is that estates of decedents represent a random draw of the living population. Once estate statistics are compiled, the next step is to use the estate multiplier technique and create a representative sample of the living. Due to exemption limits, estate returns capture predominantly the wealthy and hence death selects a sample of rich, living people. For stratified data, if the mortality rate within any socio-economic group is $m_{i}$ then each estate $P_{i}$ represents wealth for $P_{i} \cdot m_{i}{ }^{-1}$ individuals where $m_{i}{ }^{-1}$ is the estate multiplier. One important distinction between the model used here and those in other studies is that each estate stands for $m^{-1}$ tax units rather than individuals (see discussion on population controls in Appendix A.2)

A slight disadvantage in the Indian case is that there are no available micro-data at the estate level, which give details on gender and age for the decedents. This practice is more common in administrative records of developed countries with a history of reliable data. Instead, as discussed, the Indian direct tax authority (CBDT) preprocesses its assessments into wealth brackets and separately reports a breakdown of total wealth into categories such as movable and immovable wealth. Should age and gender data become available in the future, then even more precise estimates maybe possible. For the purposes of this paper, all estates use the same multiplier (i.e $m_{i}=m$ ) with appropriate attention given to measuring mortality consistently across the population.

The estate multiplier is not without shortcomings - mostly related to whether decedents represent a random draw of the population. An excellent discussion and conceptual resolution of these issues 
(including relevant literature) is contained in the appendix for Kopczuk and Saez (2004). To put it briefly, decedents may draw down their wealth in expectation of death or may even incur expenses related to illness as they age. If estate holders are aware of their looming mortality then their wealth accumulation patterns would also be different, particularly in the context of lifecycle or bequest savings by the living. One way we have already overcome some of these limitations is that the value of estates used in this paper corresponds to the principal value of the estate (discussed previously). Hence adjustments have already been made for various death-related expenses such as funeral costs, debts and costs associated with realization of property. In the context of India, we can also assign very high relative importance to tax evasion. Registration of property and financial assets in the inheritance process are not as easily avoidable and hence we may point to the pre-discussed superiority of estate data over other potential sources of personal wealth. The incentive to transfer assets as gifts was also kept in check through the gift tax for the entire period covered in this paper. From the estate multiplier model, the population I construct can cover less than $1 \%$ of the total tax units (I only report shares starting from the top $0.1 \%$ ) - wealth accumulation patterns therefore are not universal to the Indian population but only within the elite.

\section{B.1 Mortality tables}

Since much of India lived in poverty and disparity was (and still is) very high throughout the period of study, mortality rates for the population would not be representative of the elite classes. One of the frequent concerns of the estate multiplier being biased are that the wealthy have access to better healthcare and lower mortality rates. For this reason, I construct mortality tables using baseline estimates of Indian assured lives Joshi and Venkataraman (1980). This series itself uses an actuarial study by the Life Insurance Corporation of India (LIC) for the 1970-73 period. Since only rich and employed persons would be able purchase insurance, these tables represents a more appropriate mortality indicator for top wealth holders. Due to the lack of age specific data on decedents in the estate sample, I use the male adult population for India through 1961-1986 as weights for the LIC (1970-73) mortality table to compute a time series for mortality rates of wealthy Indians. If microdata on estates was available with the (age of decedents listed) then a more precise multiplier could in principle be constructed. The strategy under data constraints is to assign the distribution of males by age as a proxy for the probability distribution of decedents' ages. The adult male population (age 20 onwards) series is sourced from the World Bank's Health, Nutrition and Population Statistics. Age brackets are further compressed between ages 30-80 to avoid skewing the series towards the young (very low mortality rates) and adjusting for the fact that it takes time to accumulate wealth. The aged (above 80, high mortality rates) would be most likely to transfer or de-accumulate wealth in anticipation of death hence their accumulation behavior and wealth may be less representative than living wealth holders.

There are at least two ways that the mortality rate itself may cause a bias in the the estimations of wealth. Firstly, it may be the case that decedents in the estate tabulations are densely packed within a specific age bracket (such as say 60-65). In this case, the estate multiplier overestimates wealth because $m$ is too low (the young are counted) and hence the multiplier $m^{-1}$ is biased upward. Secondly, mortality rates may evolve over time and not remain constant. Although I use time series from the adult male population as weights, the underlying mortality table is always the same. This concern can be mitigated with the overall consensus that mortality rates change over very long periods and the last major transition, as per Joshi and Venkataraman (1980), had already happened many decades prior to their study. 


\section{B.1.1 Gender}

Mortality tables for assured Indians tended to use only Hindu males in their estimations, going back to various studies conducted by the Oriental Insurance group in British India. Although primogeniture was made obsolete by the Hindu Succession Act of 1956, it is well known that Indian women in general tend to face disadvantages in inheritance, regardless of their order of succession. This act limited direct inheritance rights of daughters to the father's separate property while sons had rights over all property, including assets under control of the Joint Hindu Family - particular to which is land. Some states amended this act starting in 1986, but its role in a de-facto male primogeniture cannot be understated and specifically for our period of study. In fact, early reports of the Estate Duty statistics have an estate rebate for money earmarked for marriage of female relative. The limited to non-existent role of women in inheritance proceeds or control of family wealth is addressed in Dyson and Moore (1983) and more extensively studied in Deininger et al. (2013). The latter study found the existence of biases against female inheritance even after significant amendments to the Hindu Succession Act. Based on these, at least crudely it may be hypothesized that wealth holders are more likely to be male (or at least male patriarchs in the tax unit) hence I use only male age-specific distributions for decedents.

\begin{tabular}{rlrr}
\hline & Age & LIC mortality table $(1970-73)$ & 1970 population weighted age mortality \\
\hline 1 & $30-34$ & 0.00150 & 0.00028 \\
2 & $35-39$ & 0.00210 & 0.00037 \\
3 & $40-44$ & 0.00340 & 0.00052 \\
4 & $45-49$ & 0.00570 & 0.00074 \\
5 & $50-54$ & 0.00940 & 0.00102 \\
6 & $55-59$ & 0.01520 & 0.00132 \\
7 & $60-64$ & 0.02420 & 0.00162 \\
8 & $65-70$ & 0.03760 & 0.00171 \\
9 & $70-74$ & 0.05740 & 0.00169 \\
10 & $75-80$ & 0.08570 & 0.00119 \\
\hline
\end{tabular}

Table 4: Mortality tables for assured Indian lives using Joshi and Venkataraman (1980) and respective weights per age category using Health, Nutrition and Population Statistics (World Bank)

For lack of better and more detailed data, the combination of estate data with male age-specific weighted mortality serves as the benchmark estimate. For comparison I have also tested a constant multiplier for the LIC table, using weights only from the 1970 age-specific distribution of males and find no significant divergence (see figure). The final number of rich Indians (i.e those above the estate tax exemption limit) is as follows:

$$
\text { no. of estates } * \frac{1}{\sum w \cdot m}
$$

Where $\sum w \cdot m$ is the weighted mortality index. To calculate total wealth is straightforward once the total number of (living) estates is computed and average wealth per estate is known. 


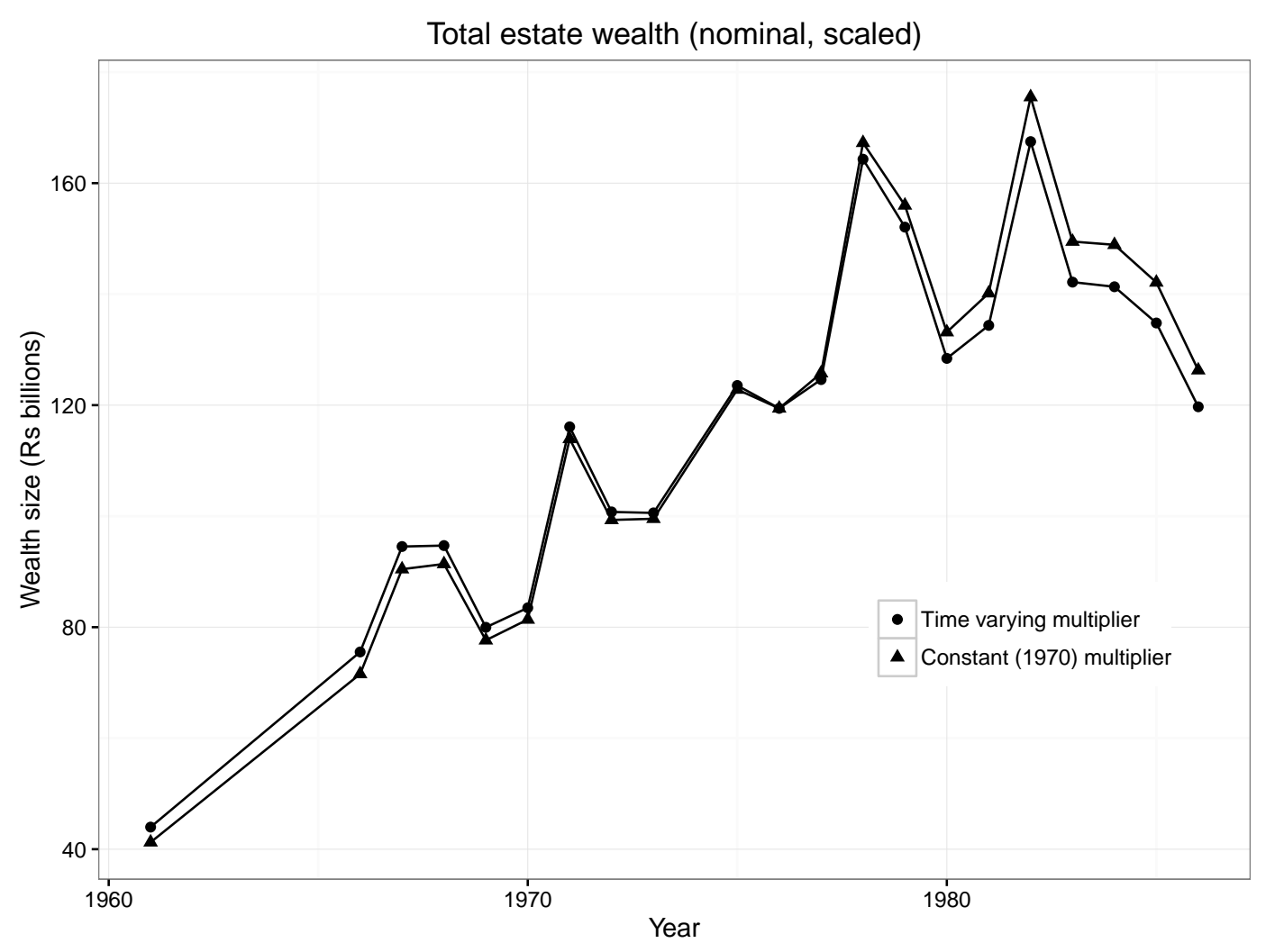

Figure 11: Total estate wealth estimation using time varying and constant multiplier

\section{Top shares}

The estate multiplier gives an estimate of the size of the rich population and their total wealth. However we still need to examine the shape of the wealth distribution. First we need to calculate the population share of the rich, obtained by dividing the multiplied estates with the total number of tax units. The time series of multiplied estates captures roughly $0.3-0.1 \%$ of the total number of tax units for the period 1961-1986. In itself this tells us a lot about wealth concentration that exemptions could only be crossed by such a small set of persons in the population.

Unfortunately there is no regular series on total personal wealth in India, which could have served as a control total for wealth shares. The CSO started maintain a household capital series sourced from the NSSO asset and liability studies but starting only in 1981. This data is collected from the perspective of studying rural indebtedness. The WWID also does not maintain a database on personal and private wealth for India. The best we can do with the data on hand is to compute the total and average wealth of various fractiles such as the top $0.1 \%, 0.05 \%$ and so on. Using the shape

of the wealth distribution within estates also allows an estimate of wealth concentration amongst the rich, captured in our data.

\section{C.1 Pareto law}

Since the various preprocessed brackets in the estate duty statistics do not coincide with precise fractiles, I use a standard Pareto interpolation to estimate the wealth of the Top 0.1\%, Top 0.05\% 
and the Top 0.01\%. The methodology is common in similar studies such as Atkinson and Harrison (1978), Banerjee and Piketty (2005), Kopczuk and Saez (2004) and Piketty et al. (2006) and goes back to the tradition of Simon Kuznets' studies of top incomes in the United States during the middle of the 20th Century.

It is a well known statistical regularity across space and time, that the top tail of wealth and income distributions tends to follow a Pareto distribution. The key property of this distribution can be summarized via the survival function (or inverse CDF) $C(w) \propto w^{-\alpha}$, where $\alpha$ is the Pareto exponent. The corresponding moments of the distribution exist if $\alpha$ is greater than the moment, so for example the mean will exist if $\alpha>1$. A corollary of the Pareto formula is the exact proportionality between average wealth above any threshold $(w)$ so that: $\frac{w^{*}(w)}{w}=\frac{\alpha}{\alpha-1}$. The graphical signature of this distribution is a downward sloping straight line when the cumulative probability is measured against wealth on the log-log scale.

Graphical plots on the log-log scale confirm that the shape of the Indian estate distribution does indeed follow a Pareto law throughout this period with fits agreeing with the CDF formula on the logarithmic scale : $\log C(w) \propto-\alpha \log w$.

\section{C.2 Interpolation}

For computing the threshold and average wealth of top groups, first the rich are computed as cumulative shares of total tax units and organized within the preprocessed brackets. To estimate thresholds for precise fractiles $\left(p_{i}\right)$ I pick a cumulative frequency and wealth $\left(f_{i}, w_{i}\right)$ such that $f_{i}$ is greater than $p_{i}$ (eg 0.0012 for the Top 0.01\%). Then the estimated Pareto coefficient for the bracket is $\hat{\alpha}=\frac{\log f_{i} / f_{n}}{\log w_{n} / w_{i}}$ where $f_{n}$ and $w_{n}$ are the frequency and wealth size for the highest bracket. Using this, the next step is to compute a parameter $y$ such that $y=w_{i} f_{i}^{1 / \hat{\alpha}}$. For any precise fractile $p_{i}$ then the threshold is simply $\frac{y}{p_{i}^{1 / \hat{\alpha}}}$. So for example, in the case of the Top $0.1 \%$ the threshold is $\frac{y}{0.001^{1 / \hat{\alpha}}}$.

Once the threshold is known, average income for the fractile is quite simple. Using the proportionality, $\frac{w^{*}(w)}{w}=\frac{\alpha}{\alpha-1}$. The RHS term $\frac{\alpha}{\alpha-1}$ is the so-called inverted Pareto coefficient, whose higher (lower) values imply a fatter (thinner) tail. Once average wealth per fractile is known, total wealth is simply the average times the total number of tax units in that fractile. Using these computations, I have constructed real and nominal series for average and total wealth of the Top 0.1\%, Top 0.05\% and Top 0.01\% from 1966 to 1986 in nominal and real terms. The real series uses CPI for deflation at 1986 prices.

\section{Undervaluation in real estate and counterfactual exer- cises}

Both transacting parties (buyer, seller) in real estate have an incentive to undervalue real estate properties under little to no fear of being caught. This has been a long standing issue in India and in particular the real estate sector frequently goes through speculative bubbles driven by undeclared capital gains. The buyer in these circumstances registers their property at a low value (paying the remainder of the full value in cash) and the seller makes a capital gain hidden from the reach of tax authorities. A full discussion of these issues including sources of unreported capital gains in the Indian context along with the various measures and administrative interventions for the period of 


\begin{tabular}{rrrrrr}
\hline & Year & Number of Estates & Value of Estates (Rs 000) & Average Estate Value (Rs 000) & Estate multiplier \\
\hline 1 & 1961 & 2514.00 & 431500.00 & 171.64 & 100.89 \\
2 & 1966 & 4791.00 & 748700.00 & 156.27 & 97.41 \\
3 & 1967 & 5283.00 & 946281.00 & 179.12 & 96.97 \\
4 & 1968 & 5543.00 & 956081.00 & 172.48 & 96.60 \\
5 & 1969 & 5028.00 & 812313.00 & 161.56 & 96.15 \\
6 & 1970 & 4765.00 & 1191424.00 & 178.68 & 95.58 \\
7 & 1971 & 6496.00 & 1039100.00 & 183.47 & 94.71 \\
8 & 1972 & 6777.00 & 1041300.00 & 153.33 & 93.89 \\
9 & 1973 & 6354.00 & 1284900.00 & 163.88 & 93.18 \\
10 & 1975 & 8267.00 & 1249400.00 & 155.43 & 92.19 \\
11 & 1976 & 8226.00 & 1315700.00 & 151.88 & 91.63 \\
12 & 1977 & 8968.00 & 1750000.00 & 146.71 & 91.21 \\
13 & 1978 & 11015.00 & 1632000.00 & 158.87 & 90.91 \\
14 & 1979 & 10137.00 & 1393100.00 & 160.99 & 90.73 \\
15 & 1980 & 8273.00 & 1466500.00 & 168.39 & 90.67 \\
16 & 1981 & 8572.00 & 1836200.00 & 171.08 & 90.60 \\
17 & 1982 & 9325.00 & 1563800.00 & 196.91 & 90.73 \\
18 & 1983 & 8072.00 & 1557700.00 & 193.73 & 91.01 \\
19 & 1984 & 6471.00 & 1486800.00 & 240.72 & 91.35 \\
20 & 1985 & 5512.00 & 1321300.00 & 269.74 & 91.70 \\
21 & 1986 & 5396.00 & & 244.87 & 91.92 \\
\hline
\end{tabular}

Table 5: Aggregate statistics compiled from estate returns 1961-1986. All monetary values are in current prices. Source: All India Wealth Tax, Gift Tax and Estate Duty Statistics

study can be found in chapter 7 of Acharya (1986). This chapter is the best possible case study of urban Indian real estate markets on these matters.

As a counterfactual exercise, I assume the the entire non agricultural real estate component of elite wealth is undervalued. In chapter 7 of Acharya (1986), the authors did a case study of Delhi's real estate market using broker level data and audit cases of the income tax department. From the sample they estimated sales on the black market as a proportion of the actual declared value. Similar cases were studied for Bombay and Madras but with small samples and unreliable data (according to the authors). Using these values for Delhi I construct an under-reporting factor $1+\delta$ where $\delta=\frac{\text { Undeclared value }}{\text { Declared value }}$ for the years 1979-1983 (the years the authors study). This factor is constructed for both samples (brokers and income tax audit cases) For 1983-1986 I take geometric means of the previous periods. Hereafter the next step is to simply multiply the total estimate of non-agricultural immovable properties with these factors and build ratios against GDP. Accordingly, Measure 1 and Measure 2 correspond to the broker sample and income tax audits respectively. Although data is only used for Delhi firstly this is only a demonstrative exercise and secondly many urban elites could be expected to live in Delhi and so the factors are not entirely unrealistic of all India. 


\begin{tabular}{rrrr}
\hline & Year & $\delta$ (Broker sample) & $\delta$ (IT audits) \\
\hline 1 & 1979 & 0.80 & 0.50 \\
2 & 1980 & 2.08 & 0.60 \\
3 & 1981 & 1.54 & 0.66 \\
4 & 1982 & 1.46 & 0.73 \\
5 & 1983 & 1.88 & 0.91 \\
6 & 1984 & 1.48 & 0.67 \\
7 & 1985 & 1.48 & 0.67 \\
8 & 1986 & 1.48 & 0.67 \\
\hline
\end{tabular}

Table 6: Undervaluation factors sourced from estimates in chapter 7 of Acharya (1986)

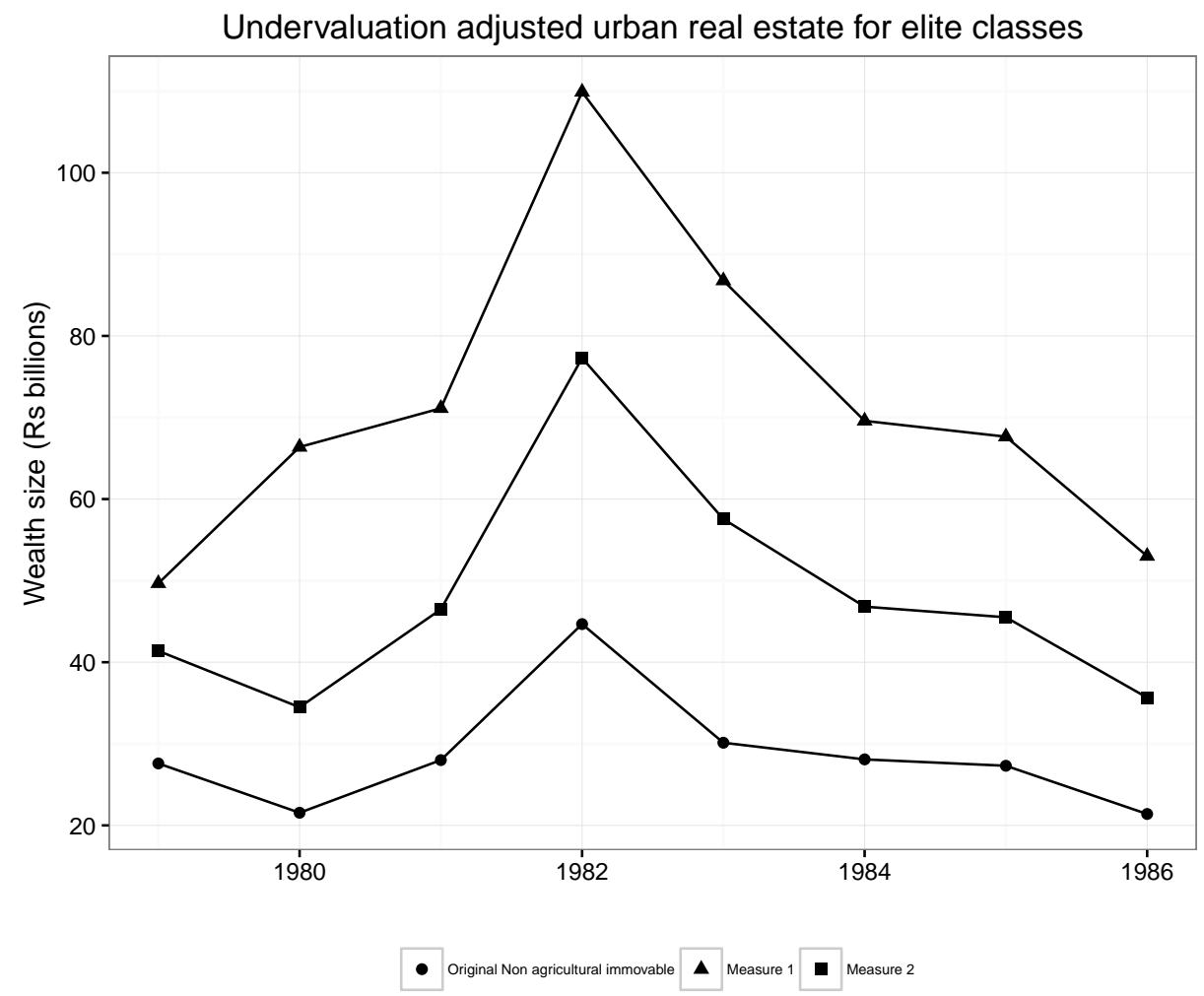

Figure 12: Counterfactual exercise on undervaluation of urban real estate. Author's computations and Acharya (1986) 